\title{
DISCRIMINATION OF ROCK TYPES AND ALTERED AREAS IN NEVADA BY THE USE OF ERTS IMAGES
}

PREPARED IN COOPERATION WITH THE

NATIONAL AERONAUTICS AND SPACE ADMINISTRATION

\author{
GEOLOGICAL SURVEY PROFESSIONAL PAPER 883
}

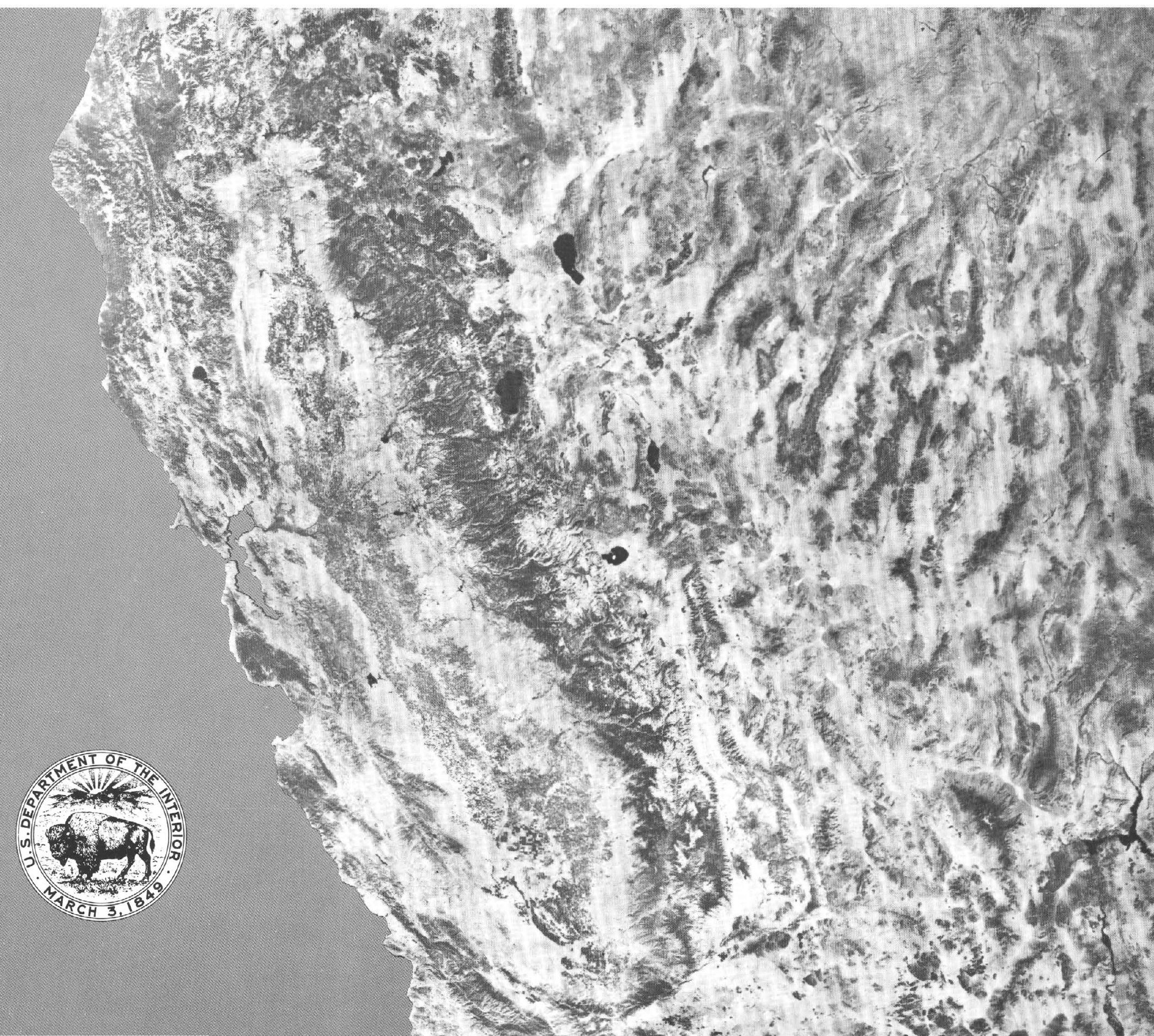





\section{DISCRIMINATION OF ROCK TYPES AND DETECTION OF HYDROTHERMALLY ALTERED AREAS IN SOUTH-CENTRAL NEVADA BY THE USE OF COMPUTER-ENHANCED ERTS IMAGES}

By LAWRENCE C. ROWAN, PAMELA H. WETLAUFER, ALEXANDER F. H. GOETZ, FRED C. BILLINGSLEY, and JOHN H. STEWART

GEOLOGICAL SURVEY PROFESSIONAL PAPER 883

Prepared in cooperation with the National Aeronautics and Space Administration

A detailed description of the development and application of a remote-sensing technique for geologic exploration

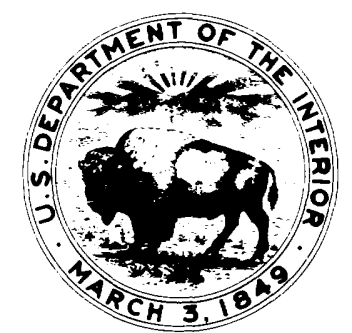


UNITED STATES DEPARTMENT OF THE INTERIOR

THOMAS S. KLEPPE, Secretary

\section{GEOLOGICAL SURVEY}

V. E. McKelvey, Director

First printing 1974 Second printing 1976

For sale by the Superintendent of Documents, U.S. Government Printing Office Washington, D.C. 20402 - Price $\$ 1.80$

Stock Number 024-001-02545-2 


\section{CONTENTS}

Abstract -.-

Introduction -...

ERTS-1 Multispectral Scanner

Visible and near-infrared reflectance of rocks and minerals

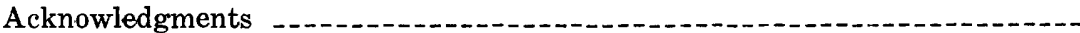

Computer image enhancement

Digital methods -...

Geometric corrections _............

Contrast stretching -

Atmospheric effects

Ratioing

Display products

Geology of the study area

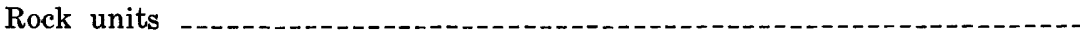

Geology of the Goldfield mining district ....

Structural geology _..........

Geologic interpretation of images _.

Standard MSS images _._-

Stretched MSS images _.

Color-infrared composites _...

Stretched-ratio images

Color-ratio composites _.......

Analysis of color-ratio composite

Discussion

Summary and conclusions

References cited

\section{ILLUSTRATIONS}

FIGURE 1. Diagram showing multispectral scanner ground-scan pattern...-.

2. Graphs showing visible and near-infrared reflectance spectra for selected mafic and felsic rocks

3. Flow diagram showing sequence of steps used in processing computer-compatible tapes and the five image products generated .-

4. Schematic histogram showing contrast stretching of digital numbers for a typical ERTS MSS scene

5. ERTS mosaic of Nevada showing location of study area

6. Geologic map of study area

7. Map showing areas of alteration in the Goldfield mining district --

8. Color aerial photograph of part of the Goldfield mining district ---

9. NASA Skylab color photograph of part of study area

10. Standard unenhanced ERTS MSS images of study area

11. Standard ERTS MSS image of study area for band 7

12. Map showing major mining districts in study area

13. Linearly stretched ERTS MSS images of study area

14. Linearly stretched ERTS MSS band 7 image of study area

15. Color-infrared composite of study area

16. Linearly stretched-ratio ERTS MSS images of study area

17. Color-ratio composite of south-central Nevada

18. Maps showing distribution of anomalous color patterns representing altered outcrops in the study area. Inset is alteration map of Goldfield district

19. Map showing major mining districts in study area

20. Graph showing reflectance spectra for alteration minerals 


\section{TABLE}

TABLE 1. Ratios calculated for MSS bands for selected mafic and felsic rocks

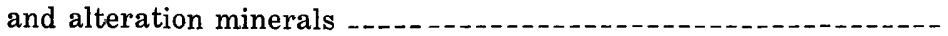




\title{
DISCRIMINATION OF ROCK TYPES AND DETECTION OF HYDROTHERMALLY ALTERED AREAS IN SOUTH-CENTRAL NEVADA BY THE USE OF COMPUTER-ENHANCED ERTS IMAGES
}

\author{
By Lawrence C. Rowan, Pamela H. Wetlaufer, Alexander F. H. Goetz ${ }^{1}$, \\ Fred C. Billingsle $Y^{1}$, and John H. Stewart
}

\begin{abstract}
A combination of digital computer processing and color compositing of ERTS Multispectral Scanner (MSS) images has been used to detect and map hydrothermally altered areas and to discriminate most major rock types in southcentral Nevada. The technique is based on enhancement of subtle visible and near-infrared reflectivity differences associated with variations in bulk composition. MSS spectral bands are ratioed, picture element by picture element, by computer and are subsequently contrast stretched to enhance the spectral differences. These stretched-ratio values are used to produce a new black-and-white image which shows the subtle spectral-reflectivity differences and concurrently minimizes radiance variations due to albedo and topography. Additional enhancement is achieved by preparing color composites of two or more stretched-ratio images. Color variations seen in these color-ratio composites represent spectralreflectance differences.
\end{abstract}

The choice of MSS bands for ratioing depends on the spectral-reflectance properties of the surface materials to be discriminated. For south-central Nevada, the most effective color-ratio composite for discriminating between altered and unaltered areas and among the regional rock units was prepared using the following color and stretched-ratio image combination: blue for MSS 4/5, yellow for MSS 5/6, and magenta for MSS 6/7. In this composite, mafic rocks, mainly basalt and andesite, are white whereas felsic extrusive and intrusive rocks are pink. The felsic rocks are especially notable because they have a large intrinsic albedo range, which commonly prevents their discrimination from mafic rocks in other types of images and photographs.

Altered areas are represented by green to dark-green and brown to red-brown patterns in the color-ratio composite. Except for two areas, the green areas represent hydrothermally altered, commonly limonitic rocks. The dark-green, brown, and red-brown patterns are less prevalent. Darkgreen areas are limonitic and limonite-free altered rocks. Areas that are brown in the color-ratio composite have been studied in less detail, but they appear to be predominantly light-colored hydrothermally altered volcanic rocks. The redbrown pattern represents limonite-free, silica-rich lightcolored volcanic rocks that have conspicuous alteration in two areas and questionable alteration in two other areas.

Altered outcrops mapped from the color-ratio composite

\footnotetext{
1 Jet Propulsion Laboratory, California Institute of Technology, Pasadena, Calif.
}

show a pronounced coincidence with known mining areas. In the Goldfield mining district, the most productive in the study area, the degree of agreement between the green patterns and the previously mapped alteration zone is striking. These altered areas are not apparent on the individual MSS images, color-infrared composites, or color photographs obtained from NASA's Skylab. Therefore the technique used in this study appears to have important applications in mineral-resources exploration and regional geologic mapping. Future research should focus on refinement of this technique, especially on defining more clearly the relationships between visible and near-infrared spectral reflectivity and mineralogical composition and on testing the technique in a variety of geologic settings and environmental conditions.

\section{INTRODUCTION}

The first Earth Resources Technology Satellite (ERTS-1) provides an important new tool for geologic exploration in the form of small-scale multispectral visible and near-infrared images. These images, which show large areas under nearly constant lighting conditions, already have been applied to a wide variety of geologic problems ranging from detection and delineation of fault zones and volcanic centers to studies of coastal erosion and sediment transport. Most applications, however, have relied mainly on photointerpretation of these synoptic views rather than on multispectral-reflectance analysis. Regional morphologic features are commonly quite conspicuous, but visible and near-infrared spectral-reflectance differences among rocks are usually small and therefore not readily apparent through visual examination of the images.

A technique which combines digital computer processing and color compositing has been devised for enhancing subtle spectral-reflectivity differences. This technique has been applied to part of an ERTS-1 image of south-central Nevada with emphasis on the Goldfield mining district. Analysis has focused on discrimination of the geologic materials, 
especially in mineralized areas, on the basis of visible and near-infrared spectral-reflectivity differences. This report presents the geologic interpretation and evaluation of the resulting processed images. Brief descriptions are given of the ERTS-1 mission profile and imaging subsystem, the general nature of the visible and near-infrared spectral reflectivity of rocks, and the techniques used.

\section{ERTS-1 MULTISPECTRAL SCANNER}

ERTS-1 was launched by the U.S. National Aeronautics and Space Administration (NASA) on July 3,1972 , and is stabilized in a near-polar orbit approximately $907 \mathrm{~km}$ above the earth. The satellite contains two imaging systems, the Multispectral Scanner (MSS) and the Return Beam Vidicon $(\mathrm{RBV})$, which record reflected visible and nearinfrared radiation. A third system, the Data Collection System (DCS), receives and relays data from earth-based monitoring instruments. The sun-synchronous orbit allows 14 orbits each day and coverage of the same area every 18 days at the same local solar time, which is 0942 hours at the equator.

Data for North America, Hawaii, and Iceland are transmitted directly to the nearest of three NASA receiving stations-Greenbelt, Md., Goldstone, Calif., and Fairbanks, Alaska. Images of selected areas beyond the reception capability of these stations are recorded on tape and transmitted at a later time, but tape-recorder malfunctions have limited the coverage of such areas.

Although the RBV was turned off in August 1972 after an electronic malfunction, the MSS has recorded thousands of images that have high spatial resolution and radiometric fidelity. Solar energy reflected from the Earth's surface is measured in four spatially registered spectral bands through the same optical system.

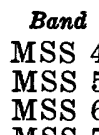

MSS 4

MSS 6

Wavelength, $\mu m$ $0.5-0.6$

$.6-.7$

$7-8$

$.8-1.1$

The analog electronic signal, along with internal calibration measurements, is transmitted to the ground where it is digitized and formatted into a digital data stream. Geometric and radiometric calibration is achieved in a ground-based digital computer.

The MSS scans cross-track (west to east) swaths $185 \mathrm{~km}$ wide, imaging six scan lines across in each of the four spectral bands simultaneously (fig. 1). This scanning provides continuous coverage along each orbital track. The data are converted to pic-

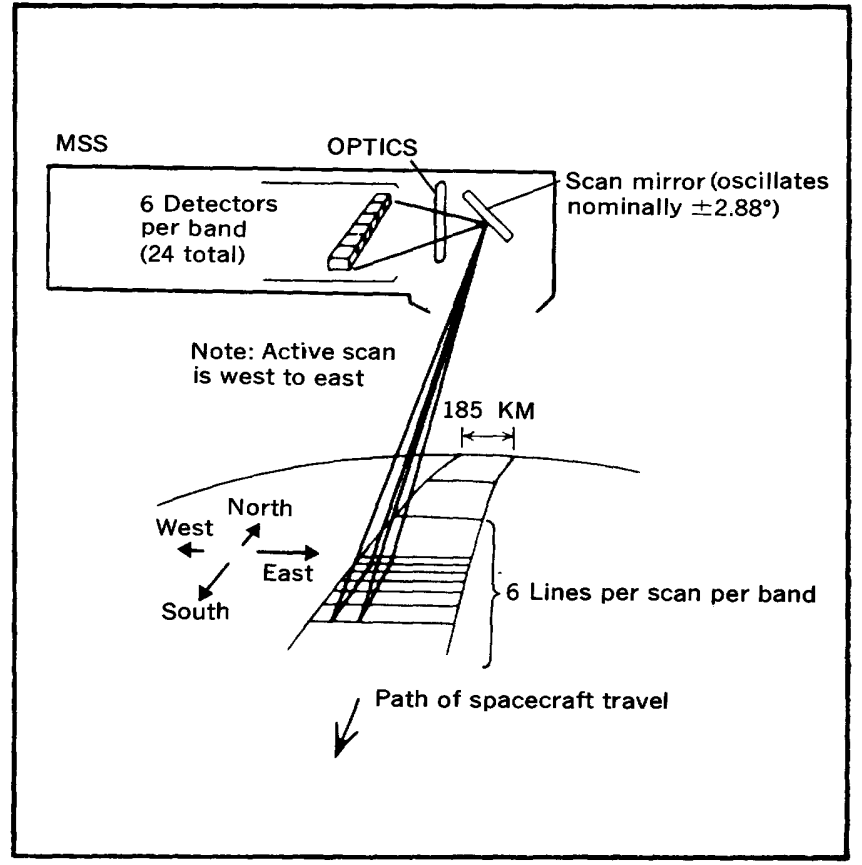

FIgURE 1.-Multispectral Scanner ground-scan pattern. Schematic diagram shows the relations between spacecraft attitude and image geometry (U.S. Natl. Aeronautics and Space Admin., Goddard Space Flight Center, 1971).

torial images and are framed at the Goddard Space Flight Center, Greenbelt, Md., with a 10-percent forward-lap between adjacent scenes. Side-lap depends on latitudinal position; it ranges from about 14 percent at the equator to 50 percent at lat $54^{\circ} \mathrm{N}$. or S. Each frame covers approximately $34,200 \mathrm{sq}$ $\mathrm{km}$. Spatial resolution for the images averages about $80 \mathrm{~m}$ but is appreciably higher for high-contrast linear features.

\section{VISIBLE AND NEAR-INFRARED REFLECTANCE OF ROCKS AND MINERALS}

Our understanding of the relationships between mineralogical composition and visible and nearinfrared spectral reflectivity is based mainly on published laboratory measurements (Hunt and Salisbury, 1970; Ross and others, 1969; Hunt and others, $1971 a, b ; 1973 a, b ; 1974 a, b)$. All these measurements were made on crushed, homogeneous, and generally unaltered samples. Although application of these data to analysis of MSS images of large geologically complex areas is made difficult by several factors, especially scale differences and surface-state conditions, the laboratory data do provide a framework for initial investigations.

Analysis of these laboratory spectra show that electronic transitions in constituent metal ions result 
in broad optical absorption bands in the ultra-violet, visible and near-infrared wavelengths. For example, iron, the most common transitional metal ion, has conspicuous ferrous and ferric absorption bands centered at about 1.0 and $0.92 \mu \mathrm{m}$, respectively, and several closely spaced weaker bands between 0.40 and $0.55 \mu \mathrm{m}$ (Hunt and Salisbury, 1970). Other transitional metal ions that give rise to absorption bands include copper, titanium, chromium, and manganese (Hunt and others, 1971a,b). Absorption bands due to vibrational processes in water and hydroxyl molecules also occur in the near-infrared wavelengths, but the only one of these bands within the response range of the MSS is centered at about $0.95 \mu \mathrm{m}$.

Absorption bands are commonly quite intense and therefore result in conspicuous reflectance minima, predominantly in ferromagnesian and hydrous mineral spectra. Diagnostic individual spectral features, however, are generally subdued beyond recognition by addition of anhydrous nonferrous minerals such as quartz and feldspar to form polymineralic rocks. The shape of rock spectra are nonetheless still affected by the absorption bands. For example, the reflectance of mafic and ultramafic rocks changes very little between 0.4 and $1.1 \mu \mathrm{m}$ (fig. $2 B$ ). In contrast, felsic-rock reflectance, which is generally affected less by absorption bands, increases continuously throughout this range, although at a slower rate between 0.70 and $1.1 \mu \mathrm{m}$ than at shorter wavelengths (fig. $2 A$ ). The slopes of reflectance curves for rocks with intermediate composition are typically between those of felsic and mafic rocks (Ross and others, 1969). As we will discuss later, the spectra for unaltered rocks (fig. 2) and altered rocks generally have significantly different shapes.

Differences in spectral shape can be used to distinguish among geologic materials and, in some cases, to place general bounds on their bulk composition. Several factors-including impurities both in the crystal lattice and on the surface of the rocks, atmospheric conditions, and system calibrationcomplicate both of these efforts. Surficial weathering products such as limonite and clay minerals are especially important as they obscure the original rock surface.

The characteristic spectral shapes for the rock (and soil) units can be derived from the MSS data to provide the basis for compositional estimates, although spectral details are somewhat subdued by the breadth of the MSS bands, especially band 7. Unknown atmospheric effects and system-calibration complications preclude obtaining absolute spectral reflectivities at this time. The field spectral measure-

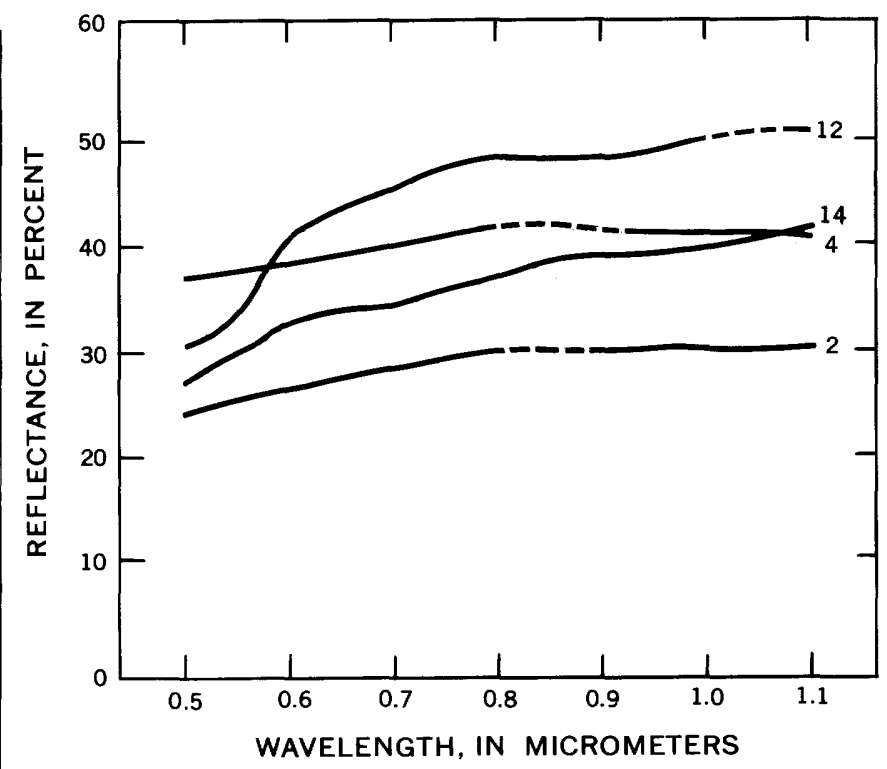

$A$

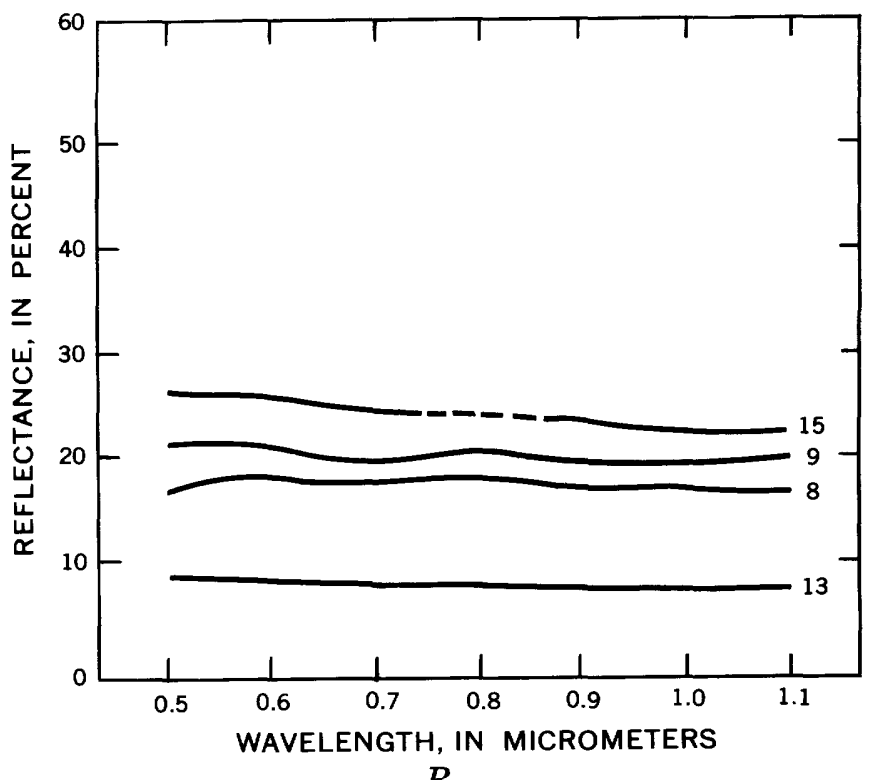

$B$

FIgURE 2.-Visible and near-infrared reflectance spectra. Spectra of samples with grain sizes in the $420-$ to $500-\mu \mathrm{m}$ range (modified from Ross and others, 1969). A, Selected felsic rocks, rhyolite (12), granite (14), rhyolite (4), granodiorite (2), showing increasing reflectance. $B$, Selected mafic rocks, serpentinite (15), gabbro (9), peridotite (8), and basalt (13), showing overall decreasing reflectance. Dashed line where inferred.

ments needed for absolute MSS calibration are presently being made, although adequate data are not yet available. On the other hand, absolute calibration is not required for simple discrimination that depends mainly on relative reflectance differences among rock types. Rock (and soil) units can be distinguished on the basis of very subtle reflectance differences, even though the absolute spectral reflectivities 
and gross lithologies cannot yet be determined from the MSS data.

\section{ACKNOWLEDGMENTS}

This study was supported by the U.S. National Aeronautics and Space Administration under contract No. S-70243-AG to the U.S. Geological Survey and Contract No. NA57-100 to the Jet Propulsion Laboratory, California Institute of Technology. Several colleagues made many useful suggestions during the course of this study, and we are especially grateful to Kenneth Watson, Terry Offield, and Allan Kover of the U.S. Geological Survey, who reviewed the manuscript. Alan Gillespie, Jet Propulsion Laboratory, did most of the computer processing. Allan Kover developed the diazo processing technique used in preparing the color-ratio composites.

\section{COMPUTER IMAGE ENHANCEMENT}

Development of image-processing techniques has been greatly stimulated during the last 10 years by the widespread use of imaging devices in planetary and, more recently, terrestrial remote sensing. Enhancement techniques now range from the relatively simple single-band contrast enhancement to twodimensional filtering in spatial or Fourier domain to complex cluster analysis, sometimes coupled with ratioing of spectral bands.

The picture data can be taken from film images by scanning densitometry or, as in the case of the ERTS MSS, taken directly from computer-compatible tapes (CCT). Tape-recorded digital data are preferable because on film accuracy is lost in recording radiometric information and is further degraded by duplication, and scanning introduces additional noise into the signal. Other advantages of using the tapes for analysis include considerable analytical flexibility, reproducible results, and relatively reasonable costs.

Film methods were used in one of the earliest successful attempts (Whitaker, 1965) to discriminate rock units on lunar photographs on the basis of spectral reflectivity. In the apparently uniform regolith of Mare Imbrium, two basaltic lava flows were distinguished in a black-and-white composite produced by masking blue and infrared wavelength telescopic photographs. Using a similar approach, but manipulating digitized multiband telescopic photographs in the computer, a method was devised for analyzing Apollo orbital multiband photographs (Billingsley and others, 1970; Goetz and others, 1971). An extension of this technique, using a photographic ratio method, was developed by Yost, An- derson, and Goetz (1973). During this same general period, Vincent and Thomson (1972) were ratioing thermal-infrared spectral images to detect emissivity variations related to chemical and mineralogical differences. These results, along with the evaluation of laboratory spectra described in the previous section, made clear the considerable potential of ratioing for multispectral analysis of ERTS data (Rowan and Vincent, 1971).

Ratioing is an effective method for distinguishing among rock types because the main spectral differences in the visible and near-infrared spectral regions are found in the slopes of the reflectivity curves; individual absorption bands are broad and weak and therefore cannot be used in most cases for discrimination of rock type on the standard MSS images. In addition, areas of interest geologically generally have some vertical relief. The ratioing process removes first-order brightness effects due to topographic slope and allows attainment of higher image contrast through additional processing. On the other hand, terrain effects are highly disturbing in color-additive displays or in analysis by clustering methods based solely on brightness.

Although digital computer processing ultimately proved to be necessary for this study, attempts were made to use more rapid visual and optically assisted techniques. Visual comparison of the MSS bands of many Nevada scenes resulted in only a few places where band-to-band differences could be related to rock type. For example, widespread volcanic rocks in the northern Antelope Range and Schell Creek Range in White Pine and Elko Counties are conspicuously darker in the near-infrared bands than in the visible bands (ERTS frame No. E-1053-17533, not shown). Enhancement by color-additive viewing is mainly useful for determining vegetation distribution. Although discrimination of rock units in the study area is not substantially improved by this method, color-additive techniques have proved more useful than simple comparison of individual blackand-white MSS images in other areas.

Attempts to enhance spectral-reflectance differences by compositing a negative of one spectral band and a positive of another, as described by Whitaker (1965), were also generally unsuccessful. Of the many problems, the most serious were the general lack of enhancement actually achieved and the introduction of photographic processing errors that were of the same order of magnitude as the spectralreflectance differences. In order to make the spectralreflectance differences visible, a very high film contrast is necessary. At high-contrast levels, however, 


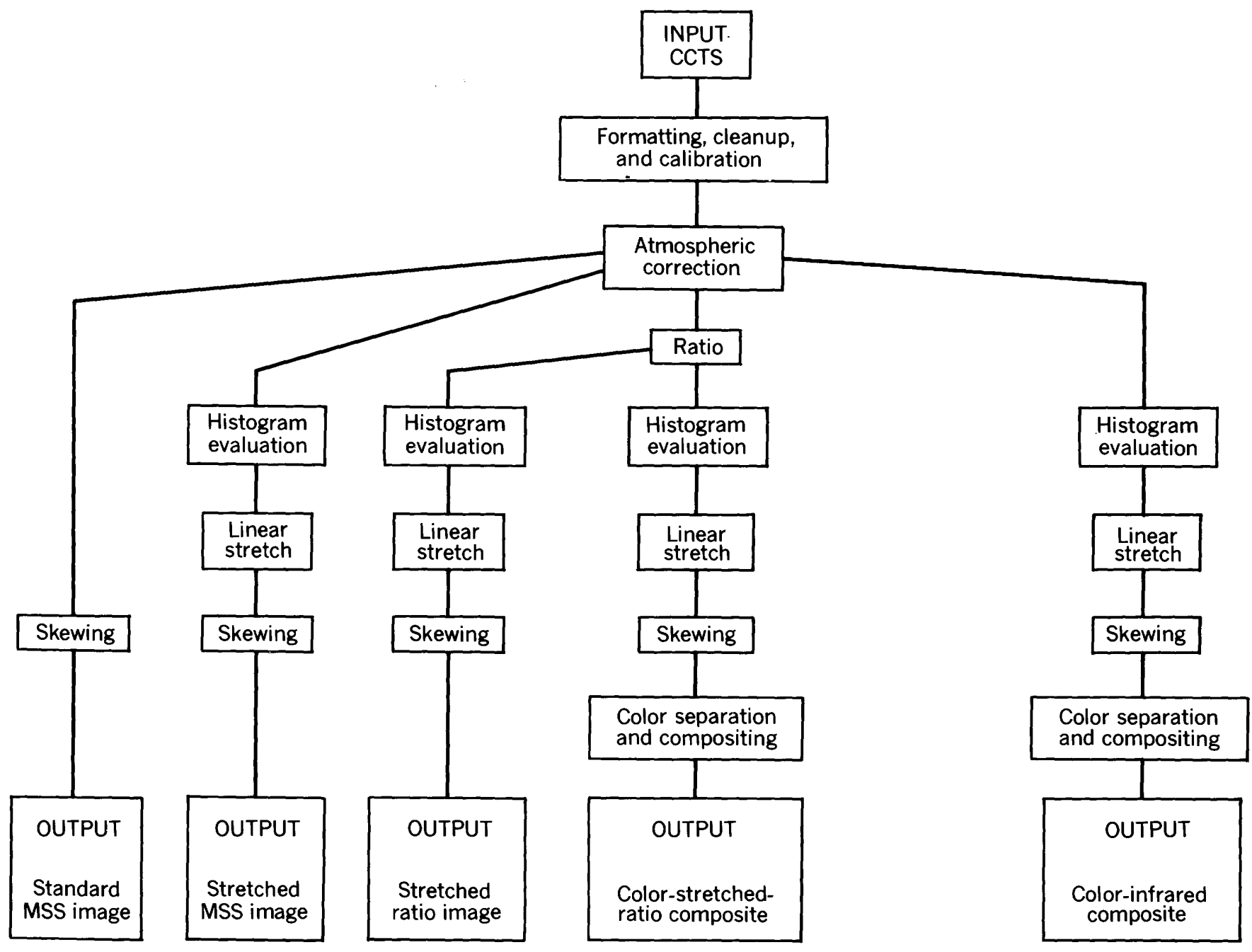

FIGURE 3.-Flow diagram showing the sequence of steps used in processing computer-compatible tapes and the five image products generated.

some important information is lost in the nonlinear part of the film response curve. Therefore, in general, purely optically assisted methods of analysis appear to have a somewhat limited value for geologic multispectral analysis.

\section{DIGITAL METHODS}

Various techniques have been developed for digital processing of images. Only those relevant to discrimination among rock materials will be discussed here. The steps in the enhancement of the MSS images are outlined in the flow diagram in figure 3.

The aynamic range of the MSS is encoded to 64 brightness levels. Application of system calibration to take care of nonlinearities results in approximately 80 brightness levels, coded to seven-bit accuracy. The digital numbers (DN) on the tape represent data values that are linear with brightness and range from 0 to 127 . For convenience in using exist- ing computer programs, the MSS data have been expanded into eight bits, resulting in a DN range of 0 to 255. Future references to DN values will refer to the eight-bit range.

Because the application of MSS on-board calibration data at the National Data Processing Facility, Goddard Space Flight Center, is not perfect, residual variations manifest themselves as a striping pattern repeated at six-line intervals. In unenhanced smallscale photographic prints, this banding is not very noticeable, but after computer enhancement and enlargement, the lack of perfect radiometric calibration is disturbingly apparent. Methods for reducing the striping pattern have been described by Billingsley and Goetz (1973) and require lengthy processing.

For each MSS scene, four CCT's are required, each containing one-fourth of a frame. If the area of interest spans an area covered by more than one CCT, strips can be reassembled or concatenated. 


\section{GEOMETRIC CORRECTIONS}

The ERTS MSS is a point-scanner device that has the scanning trace perpendicular to the downtrack direction of the spacecraft (fig. 1). Therefore, the rotation of the Earth during acquisition of each set of progressive lines of one picture will cause a lateral skewing of the area covered on the ground. This skewing is a function of latitude. Because the data are recorded on film using an orthogonal grid pattern, each successive scan line must be shifted horizontally within the grid to compensate for the skewing. The resulting output picture is in the form of a parallelogram.

An additional correction is needed to compensate for a higher sampling rate in the scan-line direction than in the downtrack direction. This distortion can be compensated for by reformatting the picture elements (pixels) either in the computer or during the analog film recording. We have chosen to make this correction at the latter stage of processing.

\section{CONTRAST STRETCHING}

The MSS system is designed to cover a large dynamic range in scene brightness to respond to the effects of sun angle and albedo variation as the spacecraft covers the globe. Consequently the brightness range of any one image will generally occupy only part of the available dynamic range, resulting in a low-contrast image. In reconstructing an image from the digital data, it is therefore desirable to stretch the DN range to increase the contrast. Stretching begins by forming a histogram plot of the number of pixels per DN value (fig. 4). The brightness values above and below which no appreciable data exist can then be located and used as stretch limits. The stretch may be linear or nonlinear.

A linear stretch increases the scene contrast uniformly over the dynamic range of the output product. The stretch limits determined from the histogram are placed at the extreme points of the dynamic range (that is, 0 to $255 \mathrm{DN}$ values), and the other points are spaced linearly between these end points (fig. 4).

In a nonlinear stretch, such as a cube-root stretch, the cube root of each $\mathrm{DN}$ value is taken. The resulting DN range is linearly stretched as above. This procedure increases local scene contrast in the dark areas at the expense of contrast in the brightest areas. In an exponential stretch, the inverse occurs. There does not seem to be a general rule of thumb that can be applied to all images in determining the required stretch parameters. Care must be taken to see that useful raw data at the extremes of the DN range are not saturated and lost.

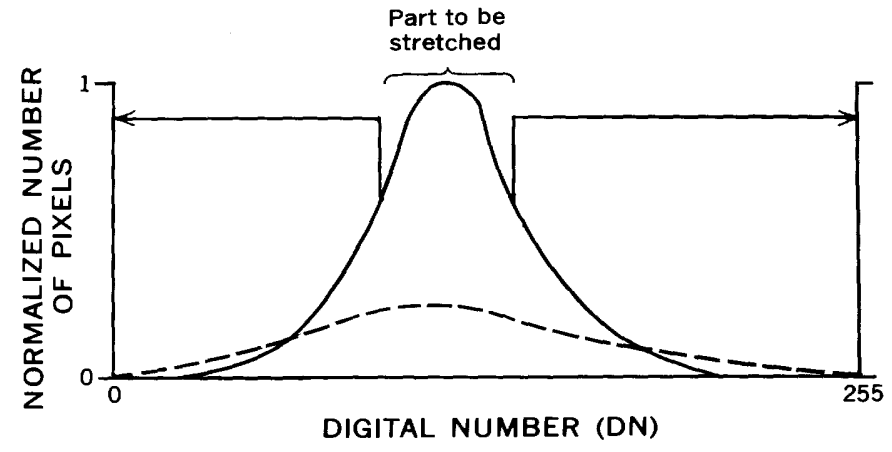

FIGURE 4.-Schematic histogram showing the distributions of digital numbers (DN) for a typical ERTS MSS scene before contrast stretching (solid line) and after linearly stretching (dashed line) a part of the DN range.

\section{ATMOSPHERIC EFFECTS}

The effects of absorption and scattering in the atmosphere vary among the different types of enhanced images. When the images are simply stretched to increase contrast, no effect is noted. If color composites are made from the stretched images, however, the relative color balance will be affected by the atmospheric scattering. The greatest effect is seen in the formation of ratios. Because

$$
\frac{A+\epsilon_{1}}{B+\epsilon_{2}} \neq \frac{A}{B},
$$

where $\epsilon_{1}$ and $\epsilon_{2}$ are the additive atmospheric-scattering components in bands $A$ and $B$, the scattering term must be removed.

The value for the atmospheric-scattering component can be determined by locating the lowest DN values in the image. These values will normally occur over water or in cloud shadows. In a study area in Arizona (Goetz, 1974), measurements of ground-reflected radiation made before, during, and after the passage of a small (about 300-m-diameter) fair-weather cumulus cloud, showed a reduction in reflected intensity by a factor of 5-6 during cloud passage. From these data we can anticipate that, to first order, most of the light received from the dark shadows is in fact atmospherically scattered sunlight. Therefore, corrections are made by subtracting the appropriate band-dependent values, determined from cloud shadows in each band, from each pixel DN value. Other methods of determining the bandto-band values may be used. The atmospheric corrections are applied to the data before skewing, stretching, and ratioing.

\section{RATIOING}

In the ratioing process, two spectral band images that have been corrected for atmospheric effects are divided pixel by pixel. The resultant image will show 
the variations in the slopes of the spectral-reflectivity curves between the two wavelength bands. Differences in albedo are suppressed, however, and very dissimilar materials easily separable on a standard photographic image may become inseparable on a ratio image because their spectral-reflectivity slopes are similar. On the other hand, a distinct advantage of this method is that one type of material will appear the same or similar in a ratio image regardless of the local topographic slope angle.

The ratio image generally shows a narrow histogram of DN values and may therefore be contrast stretched to enhance the visibility of the spectral differences. The type of stretch used, whether linear or nonlinear, as discussed, above, will determine which areas in the image are most strongly enhanced. For instance, a linear stretch will result in the visual enhancement of dark areas (low DN values in the original ratio image) and light areas (high $\mathrm{DN}$ values in the original ratio image). Other types of stretches will enhance other DN value ranges in the original ratio image.

The error introduced by scattering is greatest for low-reflectance targets. It is highest in band 4, where the scattering component may make up as much as 50 percent or more of the recorded brightness level. Band 7 has the lowest scattering component.

Although atmospheric absorption can play an important role in the form of apparent interband radiance variations, we are not able to separate these effects from variations in the MSS absolute calibration, done before we received the tapes. Band 7, spanning the $0.95-\mu \mathrm{m}$ water band, might be expected to be affected most severely by atmospheric absorption.

Residual errors, most easily detected on ratio images in highly sloped and shadowed regions, may result either from improper atmospheric correction or from the fact that such areas are illuminated mainly by the blue sky and reflections from surrounding terrain; if this is the case, the atmospheric absorption and scattering calculated from other regions is not appropriate for these areas.

\section{DISPLAY PRODUCTS}

The computer-enhanced images are recorded on black-and-white film with a flying-spot cathode-ray tube recorder. These $70-\mathrm{mm}$ transparencies can be printed on paper or combined in a color-additive process, using either a viewer, color-negative stock, or diazo transparencies. The color combination of ratio images provides the photointerpreter with a vivid display akin to a classification map.

\section{GEOLOGY OF THE STUDY AREA}

The surficial character of the study area (figs. 5, 11) makes it an ideal choice for analysis of ERTS spectral data. The topography of the test site is varied, ranging from smooth-textured alluvial basins to rugged ranges and a large mesa. Vegetation is sparse, covering 10-20 percent of the desert valleys where sagebrush is dominant, and is substantially denser only in the higher ranges where piñon pine, juniper, and grasses are predominant. Although vegetation type and distribution can sometimes reflect geology, minimal vegetation was considered preferable for these initial evaluations so that surficial features and rock units would not be obscured. The most important characteristics of the terrain are the widespread hydrothermal alteration and the broad compositional range of Tertiary igneous rocks, which provide an excellent opportunity for testing the discrimination potential of the MSS images.

\section{ROCK UNITS}

Widespread Tertiary volcanic and intrusive rocks cover approximately 95 percent of the surface of the study area not covered by alluvium (fig. 6). Precambrian and Paleozoic rocks are exposed only locally and are shown as a single unit in figure 6 . Mesozoic plutonic rocks, mainly quartz monzonite in composition, are also undifferentiated in figure 6 because of their limited distribution in the study area.

The Tertiary units exceed $6,000 \mathrm{~m}$ in thickness in a composite section; tuffs of rhyolitic, dacitic, and quartz latitic composition are the most common. Lava flows and intrusive rocks of similar compositions and of andesite and basalt are also widespread (Cornwall, 1972). Although sedimentary rocks are subordinate in the Tertiary sequence, Miocene tuffaceous sedimentary rocks are common in the central and east-central parts of the area (fig. 6). The sources for the tuffs and flows are thought to have been as many as 9 or 10 volcanic centers, several of which are within the study area (Ekren and others, 1971). Especially noteworthy are the Black Mountain and Timber Mountain calderas. The Black Mountain caldera, in the southeastern corner of the study area, was the source for the Thirsty Canyon ash-flow and ash-fall tuff (unit Tt3, fig. 6) which underlies much of the southern half of the area. Tuffs derived from the larger Timber Mountain caldera southeast of the study area are prominent in the west-central and southwestern parts of the study area. In addition, the Goldfield mining district is a volcanic center (Albers and Cornwall, 1968) and is thought to be a resurgent caldera (Albers and Kleinhampl, 1970). The volcanic and intrusive rocks of 


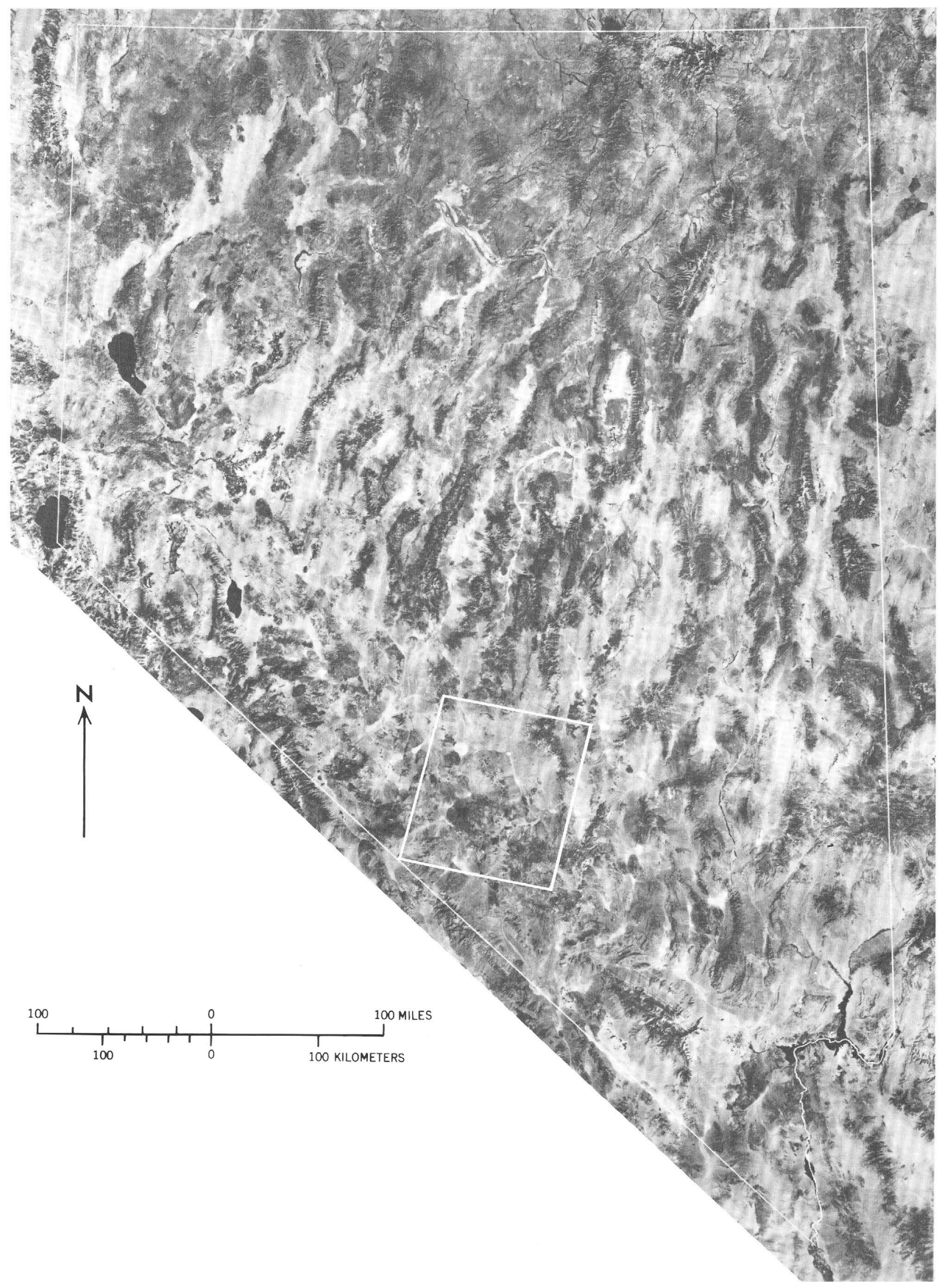


FIGURE 5.-ERTS mosaic made with MSS band $5(0.6-0.7 \mu \mathrm{m})$ images of the State of Nevada showing location of study area. Prepared by Aerial Photographers of Nevada, Reno-Stead Airport, Nev.

the Goldfield mining district are restricted to that district.

The Quaternary units consist of surficial deposits and sporadic outcrops of basalt flows and cinder cones (fig. 6). The basaltic deposits are conspicuous because of their low reflectivity relative to the adjacent materials. The surficial units, however, include complexly related alluvium, colluvium, desert wash and landslide deposits, playa materials, and, on the western edge of the area, a single exposure of bedded clay and silt (unit Qts, fig. 6). With the exception of the playa deposits, which are characterized by reasonably uniform composition and high reflectivity, these surficial deposits are lithologically heterogeneous. This compositional heterogeneity, as well as grain size, surface coatings, and vegetationcover variations, gives rise to large spectral-reflectance differences. Although the processing techniques described in the previous section appear to be potentially useful for mapping these materials, the surficial deposits present a formidable analytical problem because of their large extent and the transitional nature of boundaries. The rest of this discussion will exclude the surficial deposits; emphasis will be placed on the Tertiary units, especially where they have been hydrothermally altered.

The unaltered Tertiary volcanic and intrusive rocks have from very high to low albedos, but these variations are not a reliable guide to composition. For example, although most of the silicic rocks have high to intermediate albedos, the widespread rhyolitic Thirsty Canyon Tuff appears dark enough on the images, as well as in the field, to be mistaken for a rock of intermediate or even mafic composition. The unaltered rocks in the study area have a wide variety of muted colors, the most common being brown and gray, with green, yellow, and pink tints.

Alteration by the introduction of hydrothermal fluids and by subsequent weathering has resulted in hydration and oxidation of the Tertiary volcanic host rocks. The end products range from high-albedo clay-rich rocks, which may be locally silicified, to variably colored limonitic rocks. All the major alteration products are present in the Goldfield mining district, which is the most productive and best known altered zone in the study area.

\section{GEOLOGY OF THE GOLDFIEL.D MINING DISTRICT}

The Goldfield mining district is principally compased of Miocene volcanic rocks overlying Ordovician shale and chert and Mesozoic granitic rocks (Albers and Stewart, 1972) (fig. 6). The middle Tertiary units include air-fall and ash-flow tuff along with flows and intrusive bodies of andesite, dacite, rhyodacite, quartz latite, and rhyolite (Cornwall, 1972). Upper Tertiary basalt and welded tuff locally cap these units (Ashley, 1970). Alteration and mineralization are extensive, especially in the lower Miocene andesite and dacite, the primary ore-bearing rocks.

Ashley (1970) described two types of alteration. The older deuteric or propylitic alteration varies considerably, each variation characterizing a single volcanic unit. According to Ashley and Keith (1973), however, the chemical changes in most of these rocks have probably been quite limited. The younger intense hydrothermal alteration is more conspicuous and has a similar character in all rock units. Harvey and Vitaliano (1964) and Ashley and Keith (1973) described three mineralogically distinct zones of hydrothermal alteration. In order of decreasing alteration, silicified rocks with associated alunite, and kaolinite give way to illite-kaolinite-bearing argillized rocks, which grade into montmorillonite-bearing argillized rocks having surficial coatings of limonite and jarosite resulting from oxidation. Limonite is also common in the first two zones. The silicified and argillized rocks have a bleached appearance except where stained red and yellow by limonite and jarosite. Figure 7 shows the general limits of the alteration zones which cover more than $38.4 \mathrm{sq} \mathrm{km}$ (Ashley, 1970).

A color aerial photograph of part of the Goldfield district shows the distinctive complex mosaic of bleached clay-rich rocks and of brightly colored limonitic areas interspersed with the unaltered rocks (fig. 8). Feature A (fig. 8), an unaltered upper Tertiary basalt cap, appears dark gray; this basalt can also be identified on the alteration map of the Goldfield district (A, fig. 7) and on the enhanced images discussed later. Surrounding the basalt cap is the ore-bearing hydrothermally altered andesite and dacite, ranging from shades of light gray to red brown and brown. The red-brown hues dominate in the altered rocks. The purple-blue outcrop of unaltered latite to the northwest (B, fig. 8; B, fig. 7) can easily be distinguished from the prong of altered andesite and dacite on its southeastern border (C, fig. 8; C, fig. 7), but the northern limit of the altered rocks is difficult to determine in the color photograph. Farther east, some dark-brown-gray unaltered dacite (D, fig. 8; D, fig. 7) stands out from the nearby altered andesite and dacite. Although individual outcrops can be classified properly, the boundary of the hydrothermal alteration is difficult to define at this scale, mainly because visible color is not entirely diagnostic. 


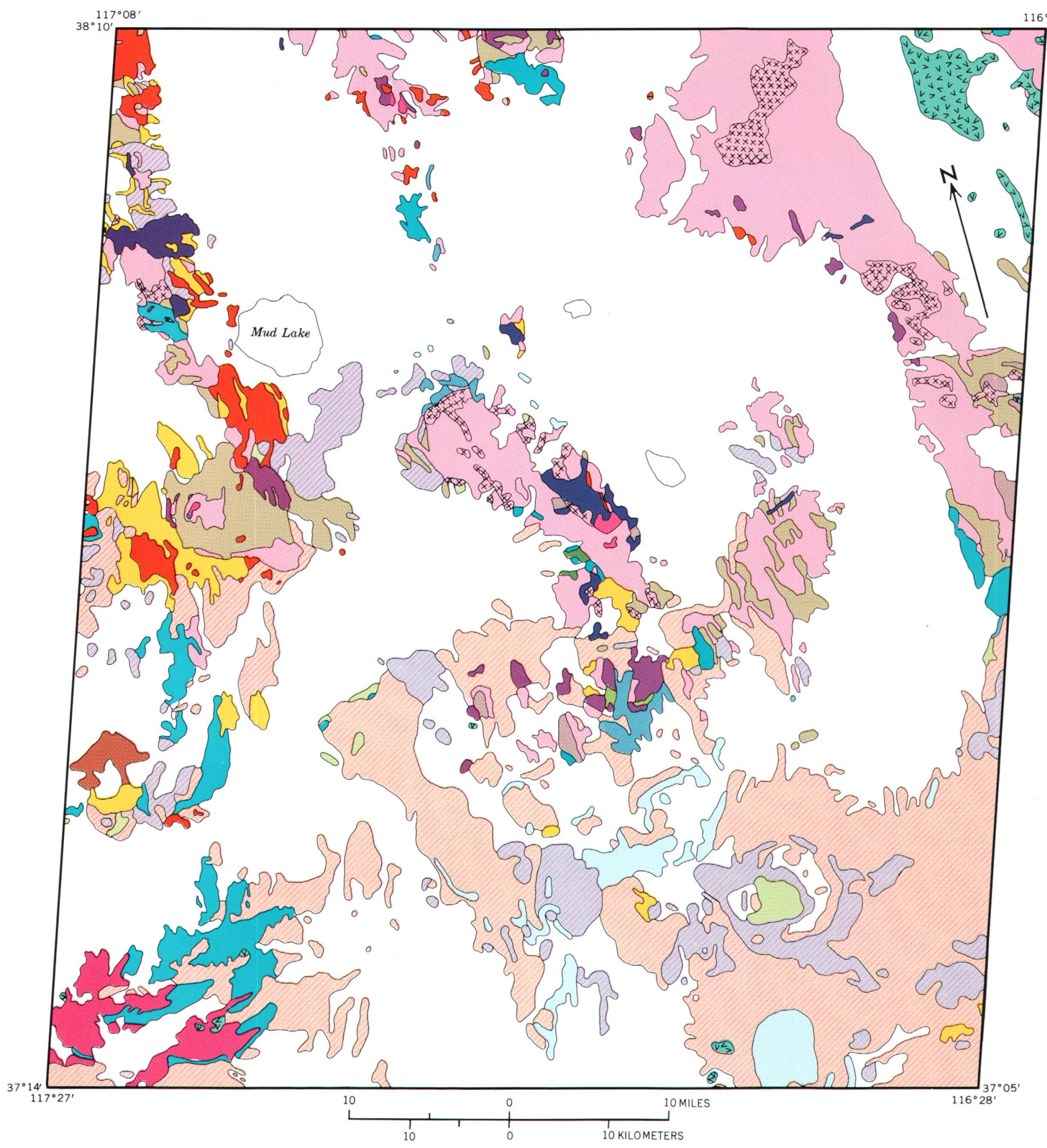


CORRELATION OF MAP UNITS

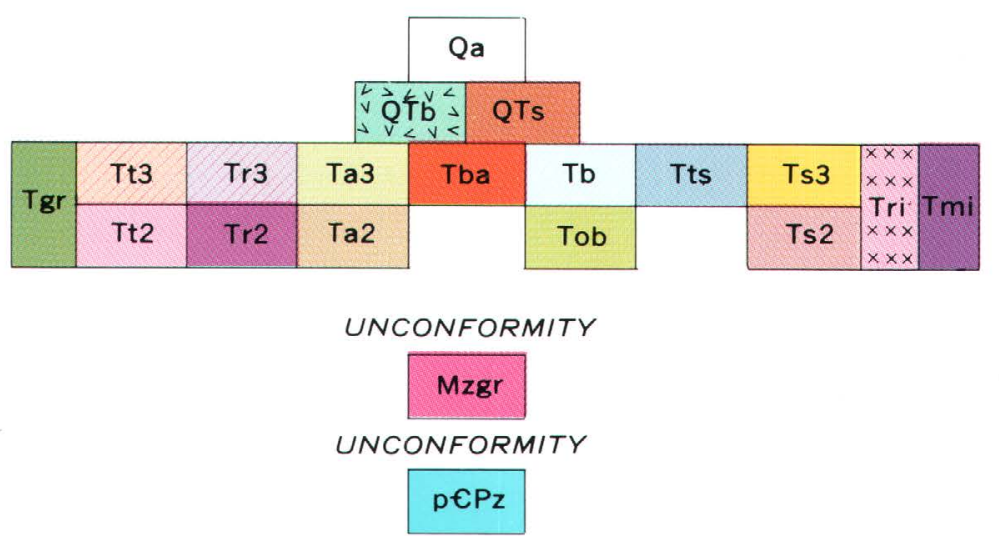

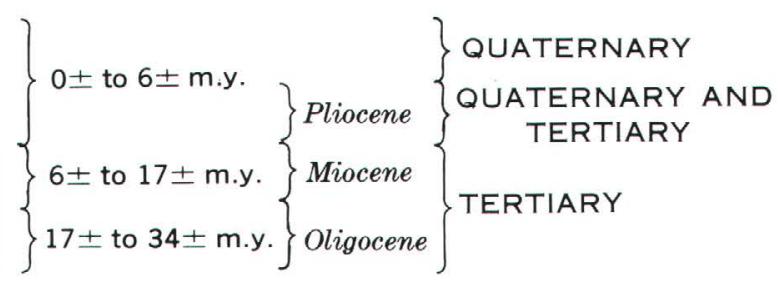

DESCRIPTION OF MAP UNITS

Qa ALLUVIAL DEPOSITS (QUATERNARY)

QTb BASALT FLOWS (QUATERNARY AND TERTIARY)

QTs SEDIMENTARY ROCKS (QUATERNARY AND TERTIARY)-Mostly lake deposits

Tgr GRANITIC ROCKS (PLIOCENE TO OLIGOCENE) - Mostly quartz monzonite and granodiorite

Tt3 WELDED AND NONWELDED SILICIC ASH-FLOW TUFFS (PLIOCENE AND MIOCENE) - Locally includes thin units of air-fall tuff and sedimentary rock

Tt2 WELDED AND NONWELDED ASH-FLOW TUFFS (MIOCENE AND OLIGOCENE) - Locally includes thin units of air-fall tuff and sedimentary rock

Tr3 RHYOLITIC FLOWS AND SHALLOW INTRUSIVE ROCKS (PLIOCENE AND MIOCENE)

Tr2 RHYOLITIC FLOWS AND SHALLOW INTRUSIVE ROCKS (MIOCENE AND OLIGOCENE)

Ta3 ANDESITE FLOWS AND FLOWS OF INTERMEDIATE COMPOSITION (PLIOCENE AND MIOCENE)

Ta2 ANDESITE FLOWS AND FLOWS OF INTERMEDIATE COMPOSITION (MIOCENE AND OLIGOCENE)

Tba ANDESITE AND BASALT FLOWS (PLIOCENE AND MIOCENE)

Tb BASALT FLOWS (PLIOCENE AND MIOCENE)

Tob OLDER BASALT FLOWS (MIOCENE AND OLIGOCENE)

Tts ASH-FLOW TUFFS AND TUFFACEOUS SEDIMENTARY ROCKS, UNDIVIDED

(PLIOCENE AND MIOCENE)

Ts3 TUFFACEOUS SEDIMENTARY ROCKS (PLIOCENE AND MIOCENE)-Locally includes minor amounts of tuff

Ts2 TUFFACEOUS SEDIMENTARY ROCKS (MIOCENE AND OLIGOCENE)-Locally includes minor amounts of tuff

Tri RHYOLITIC INTRUSIVE ROCKS (PLIOCENE TO OLIGOCENE)

Tmi INTRUSIVE ROCKS OF MAFIC AND INTERMEDIATE COMPOSITION (PLIOCENE TO OLIGOCENE)

Mzgr GRANITIC ROCKS (MESOZOIC)-Mostly quartz monzonite and granodiorite

pEPz LIMESTONE, DOLOMITE, SHALE, SILTSTONE, QUARTZITE, SANDSTONE, CHERT, AND METAMORPHIC ROCKS (PALEOZOIC TO PRECAMBRIAN)

FIgURE 6.-Geologic map of the study area. From a map of a larger area compiled by John H. Stewart and J. E. Carlson, U.S. Geological Survey; Tertiary units older than Tt2 are not present in the study area. 


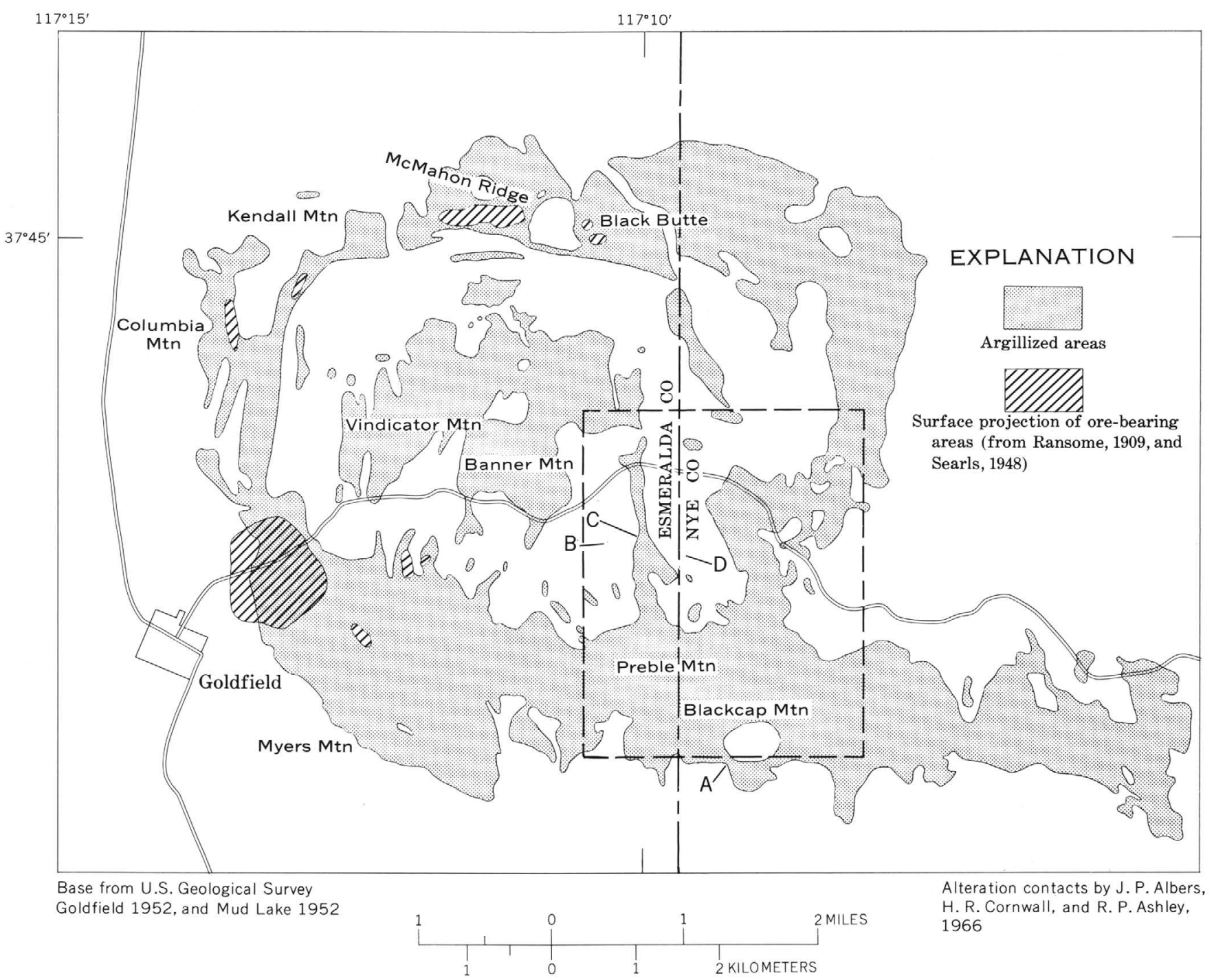

Figure 7.-Map showing areas of alteration in the Goldfield mining district (modified from Jensen and others, 1971). Area within dashed line is approximate limit of color aerial photograph in figure 8. A, unaltered upper Tertiary basalt cap; B, unaltered latite; C, hydrothermally altered andesite and dacite; D, unaltered dacite.

Although many of the rock units in the study area have characteristic colors or combination of colors, they are too muted to be consistently shown on smallscale orbital-altitude color photographs. Comparison of an excellent color photograph obtained from the S190 photographic experiment (fig. 9) with the distribution of the main rock types (fig. 6) illustrates this point. The appearance of the rocks in this photograph is dominated by albedo, which is not a reliable guide to rock type (for example, the dark-appearing Thirsty Canyon tuff, Tt3). Color differences are especially difficult to discern in the low-albedo rocks.

Except for a few small limonitic altered areas southeast of Stonewall Mountain (A, B, and C, fig. 9 ), which appear red brown, the mineralized areas are not distinctive in the Skylab photograph. For example, the Goldfield district appears mottled and slightly rust colored in a few places (D, fig. 9), but similar characteristics are also seen in unaltered areas, such as the northwest end of the Cactus Range (E, fig. 9). These characteristics are not diagnostic of altered areas. This preliminary evaluation suggests that small-scale photographs such as the Skylab example, although useful for morphological and structural studies, are not adequate for detecting and mapping mineralized areas.

\section{STRUCTURAL GEOLOGY}

Northwest-trending ranges bounded by normal faults reflect the characteristic Basin and Range terrain of the study area. High-angle normal faults bound the Cactus and Kawich Ranges and the northern and western margins of Stonewall Mountain (fig. 11) ; movement along these faults began in Mio- 


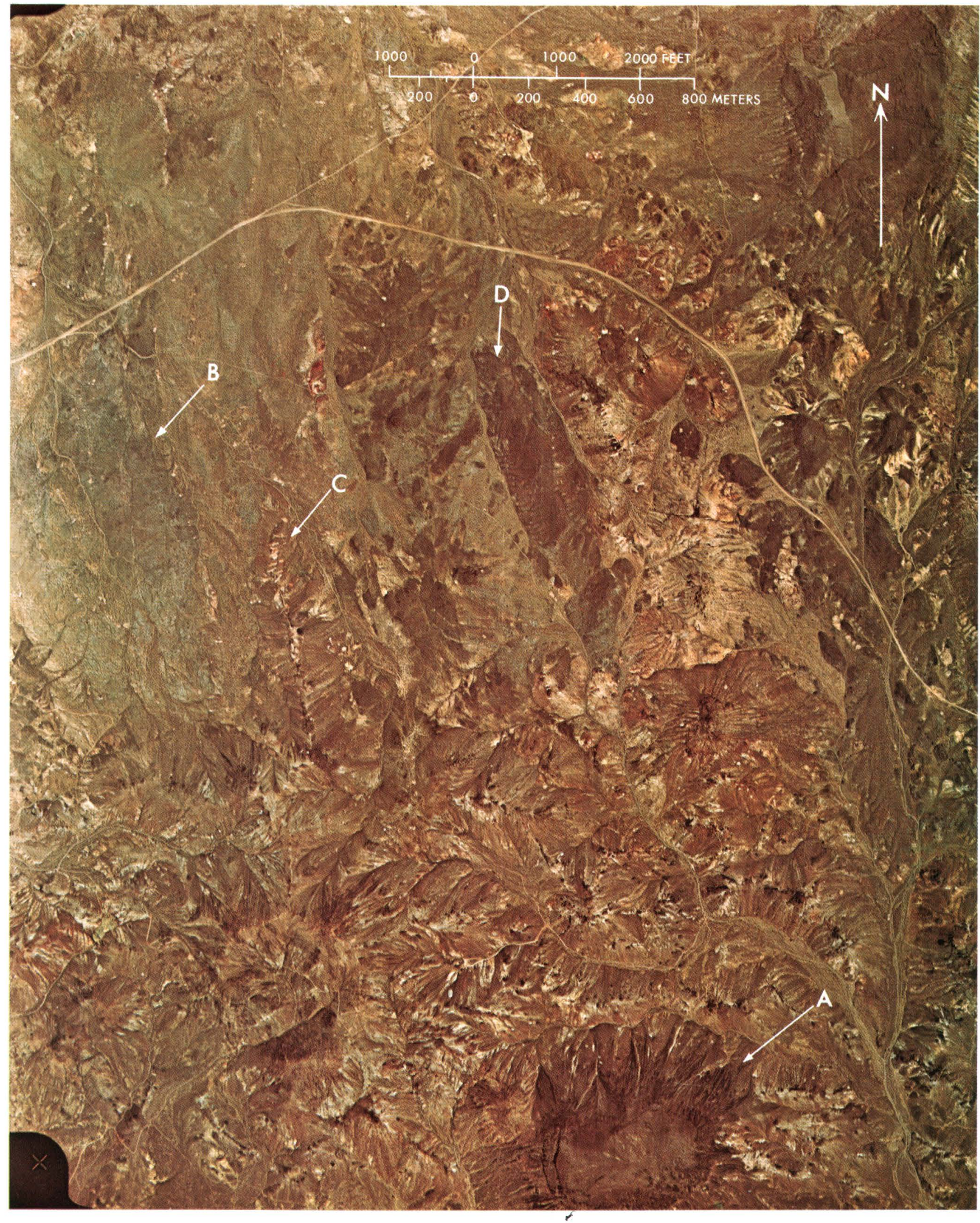

FIGURE 8.-Color aerial photograph of part of the Goldfield mining district: A, unaltered upper Tertiary basalt cap; B, unaltered latite; C, hydrothermally altered andesite and dacite; D, unaltered dacite. Photographed June 2, 1968, for the U.S. Geological Survey. Ektachrome film type 2448. 


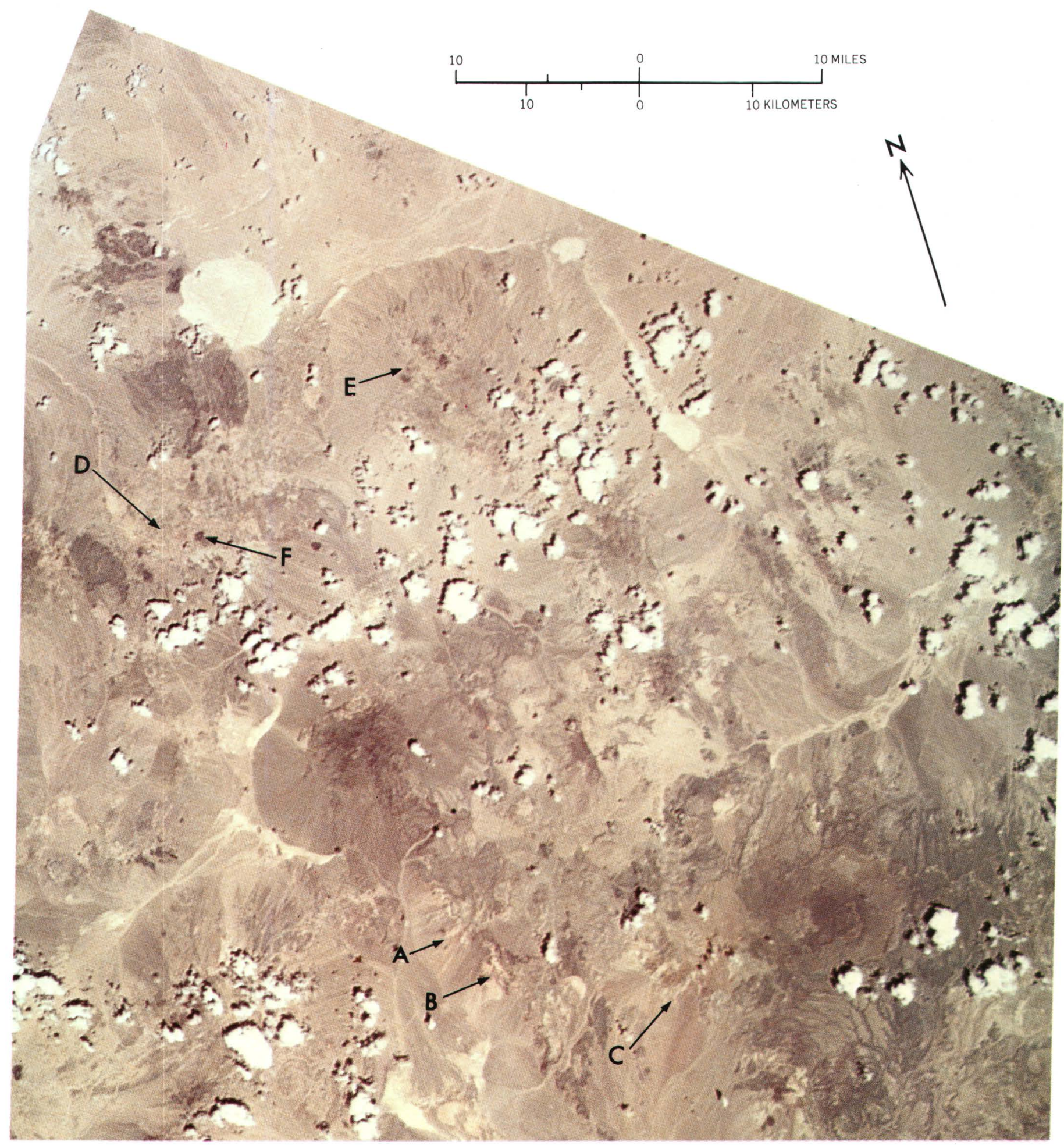

FIgURE 9.-NASA Skylab S190 photograph of part of the study area showing (A-C) alteration areas southeast of Stonewall Mountain, (D) mottled appearance of Goldfield mining district, (E) similar mottled appearance of an unaltered area, and (F) basalt cap in the Goldfield area. Photographed June 3, 1973. Ektachrome film type SO-356. 
cene time. Although in many areas the Tertiary units are highly faulted and tilted, large areas of flat-lying and undisturbed Tertiary rocks also occur (for example, Pahute Mesa in the study area).

The Precambrian and Paleozoic rocks were folded and thrust faulted mainly during Mesozoic orogeny. Right-lateral shearing of these and more recent rocks along the shear zone known as Walker Lane has resulted in mountain ranges of diverse trend. The volcanic centers mentioned above may be related to this shear belt (Ekren and others, 1971), which cuts in a northwest direction across the southern half of the study area. The structural features are not shown in figure 6 so that lithologic differences can be emphasized.

The geology of the Goldfield district is consistent with that of an early Miocene volcanic center (Albers and Cornwall, 1968). The concentric zones of successively younger formations and the alteration pattern form an east-trending elongated ellipse, and a zone of grabenlike subsidence also extends eastward. The belts of more or less linear silicified ledges may be indicative of a rim fracture system (Albers and Stewart, 1972).

\section{GEOLOGIC INTERPRETATION OF IMAGES}

Using the procedures previously described, five processed image sets (fig. 3) have been produced from the basic digital MSS tape of the south-central Nevada study area. Listed in order of increasing enhancement of spectral-reflectance information, the MSS image products are: (1) standard unenhanced images, (2) stretched images, (3) stretched colorinfrared composites, (4) stretched-ratio images, and (5) color-stretched-ratio composites (hereafter referred to as color-ratio composites).

\section{STANDARD MSS IMAGES}

The standard MSS images distributed by the NASA Data Processing Facility at Goddard Spaceflight Center are of low to moderate contrast; consequently the level of detail is low for both bright and dark objects. In the northeast part of the October 3, 1972, ERTS frame No. E-1072-18001 (fig. 10), materials with low and high albedos, such as mafic rocks and playa deposits, respectively, are distinguished easily, but little detail can be discerned within these areas. Furthermore, few differences are detectable through band-to-band comparison, except in vegetated areas, which are dark in the visible bands and light in the near-infrared bands. This general lack of band-to-band contrast testifies to the subtlety of the spectral differences among the rock types. The small magnitude of the spectral differ- ences, along with the low scene contrast of the standard images, seriously limits their value for rock-type discrimination.

Image contrast for the rocks and soils of the study area, as well as for most areas examined in Nevada and southern California, appears to be highest in the MSS image for bands 6 and 7, in figure 11 at a scale of $1: 500,000$. However, although most of the playas are easily distinguished from clouds and other features in the area on the basis of shape and texture, little confidence can be placed in most other distinctions. For example, several dark areas are quite prominent, but the compositions of the rocks in those areas range from rhyolitic to andesitic to basaltic. The two large dark patches south-southwest of Mud Lake (A) are basaltic and andesitic in composition, but three minor outcrops of tuffaceous sedimentary rocks (Ts3, fig. 6) occur in the northernmost dark area. The three small dark spots (B) on the northeastern margin of the Cactus Range are basalts, whereas the larger dark area (C) slightly to the south represents part of a mafic intrusive body. East of the Cactus Range, andesite makes up the low hills (D) that are dark on the image. The areal extent of these andesitic outcrops is exaggerated on the image because of the presence of a talus apron around the outcrop. Approximately $12 \mathrm{~km}$ south of Tolicha Peak is a series of basalt flows (E), whose boundaries do agree well with the geologic map. Although some subtle reflectivity differences among the mafic rocks exist on the image, variations are not consistent enough to allow discrimination, for example, among andesites, basalts, and the mafic intrusive body with any degree of confidence.

Not all dark areas are indicative of mafic rocks, however. The most prominent dark area on the standard MSS image in the southeastern corner represents the previously mentioned Thirsty Canyon tuff (Tt3) and a rhyolite (Tr3) (fig. 6). Only the southernmost circular area is basalt (Black Butte), and it is indistinguishable from the dark-appearing tuff and rhyolite north of it. Tuffaceous sedimentary rocks that crop out within the dark area southwest of Mud Lake are also indistinguishable from the neighboring andesite and basalt. In addition, a few small exposures of Precambrian and Cambrian rocks (F) appear dark on the image. Therefore rock-type discrimination on this standard MSS image is severly limited even if only a two-component classification system of mafic and felsic rocks is used.

In general, felsic rocks vary in tone on the image from medium to light gray. Discrimination of rock units within this tonal range of gray is rarely possible in any band, especially as the alluvium in the 

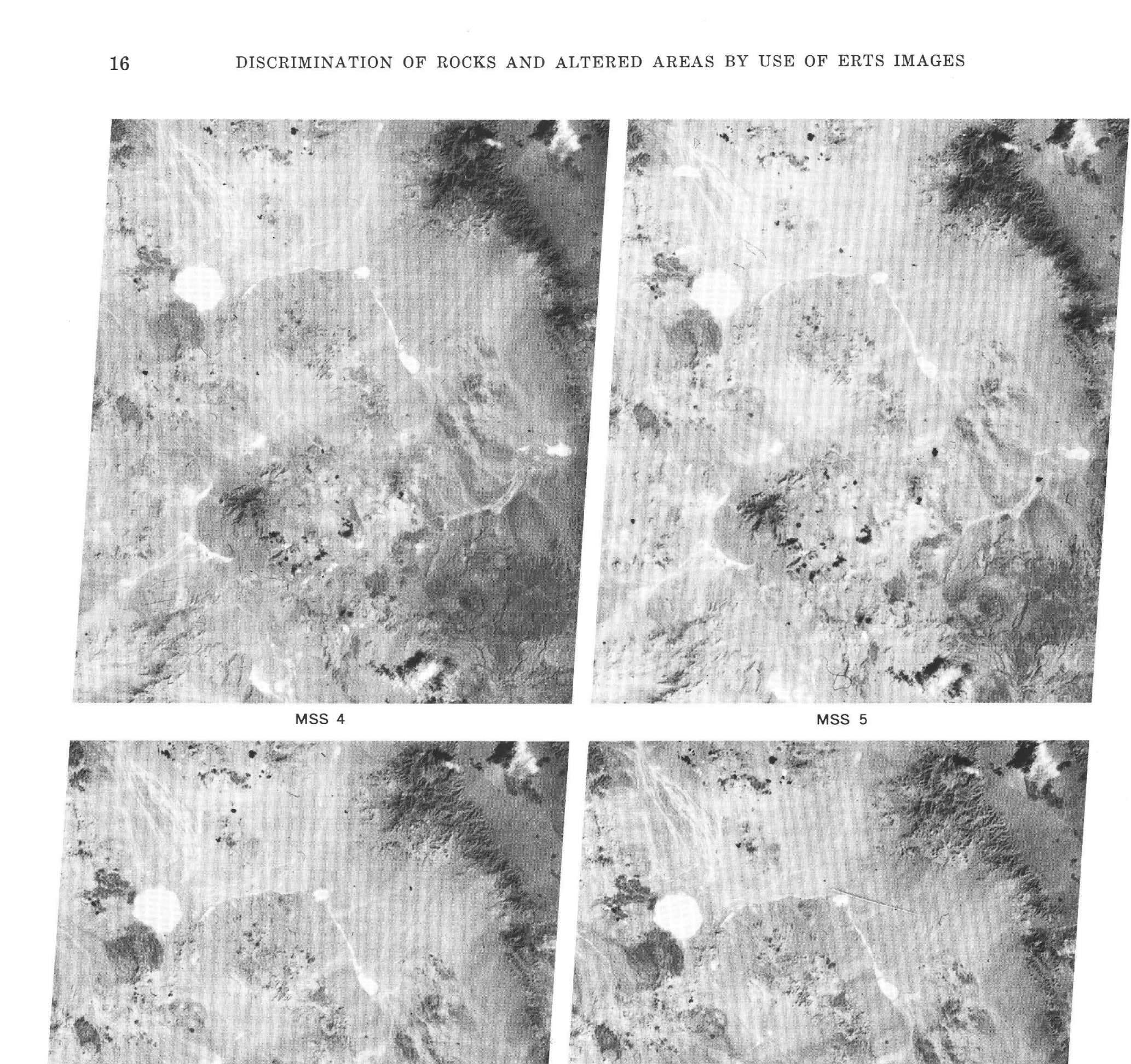
FIGURE 10.-Standard unenhanced MSS images of the study area for bands 4-7 (scale 1:1,000,000). Vegetation is 4 brighter in the image for band 7, especially in the Kawich Range (upper right), than it is in that for band 5. Imaged October 3, 1972, northeast part of ERTS frame No. E-1072-18001.

image appears as very similar gray levels. Isolated outcrops can be discriminated, however, as in the rhyolitic rocks and tuffaceous sediments $(G)$ on the westernmost margin of the Cactus Range. Nevertheless, on Pahute Mesa, the dark pattern on the image correlates only locally with the mapped distribution of tuff and rhyolite.

Major mineralized areas, as indicated by the locations of mines and mining districts (fig. 12), are not distinguishable on the image. The largest, the Goldfield district, is a uniform light gray, and the image gives no indication of the extensive alteration zone there. Other altered areas are also indistinct.

\section{STRETCHED MSS IMAGES}

The stretched MSS images of the study area (fig. 13) show substantially more scene contrast and spatial detail than do the standard images. The increased scene contrast, a direct result of the stretching process, allows slightly improved discrimination of rock types. The stretched images have been generated directly from the digital tapes with the result of an apparent increase in spatial resolution (fig. 14). The standard images (fig. 10), on the other hand, have passed through several photographic reproductive processes after their generation from the tapes, processes that have caused a loss of some resolution.

The most apparent improvement of rock-type discrimination in figure 14 is the separation of the basalt (fig. 13, A) and the mafic intrusive (fig. 13, B) in the Cactus Range on the basis of the generally lower albedo of the basalt. Other limitations on discrimination of mafic rock types, however, as described for the standard images, also apply to the stretched images. In addition, discrimination among the felsic rock units, particularly in the Pahute Mesa area, is not improved through stretching the images.

Comparison of the four images of figure 13 with the known mineralized areas (fig. 12) shows that the mineralized areas southeast of Stonewall Mountain (C) and north of the Cactus Range mafic intrusive body (B) are distinctive and bright in all the stretched MSS images. The Cuprite district (D) is notably brighter than it is in the standard images. Nevertheless, confusion could still arise in discrimination between these bright areas and other highly reflective areas such as the tuffaceous sediments south of the Goldfield district (E, fig. 13) and, in some places, alluvium (F, fig. 13). Although the Goldfield district stands out better in the stretched than in the standard images (fig. 10) because of the increased contrast, most of the mineralized areas are not prominent in the stretched images. In general, although scene contrast and apparent spatial resolution are increased, stretching of the radiance data without additional enhancement results in only slightly better discrimination of the geologic materials of this area.

\section{COLOR-INFRARED COMPOSITES}

Color composites can be prepared either by transmitting filtered light through the positive film transparencies or by combining color separates such as those made with diazo foils. For example, the color-infrared composite shown in figure 15 was prepared using blue, green, and red filters and positive transparencies for stretched MSS bands 4, 5, and 7 , respectively. Colors in this composite are directly related to the film densities in the positive transparencies. Hence, vegetation is red in this composite because the high reflectivity of vigorous vegetation in MSS band 7 compared with MSS bands 4 and 5 results in a relatively low density in the MSS band 7 transparency.

In the study area, the color-infrared composite is most useful for discrimination of vegetated areas (fig. 15). The darkest red, and therefore the densest vegetation, occurs in the Kawich Range and on Stonewall Mountain. Additional red tinges are apparent on Gold Mountain, on parts of Pahute Mesa, and north of Monitor Peak. These sparsely vegetated areas cannot be detected easily on the blackand-white stretched MSS images.

Color-infrared composites appear to offer little improvement over the stretched MSS images for discrimination of rock types. All the points of confusion among the felsic, intermediate, and mafic rock types described for the standard and stretched images are also present in this color composite. Although some of the known limonitic areas, such as southwest of Quartz Mountain (A) and north of Monitor Peak (B), are light orange brown (fig. 15), the other altered areas are not distinctive. The lightorange-brown color, suggesting high reflectance in the MSS bands 5 and 7 compared with the MSS band 4 , is consistent with limonite spectra discussed later. Nonetheless, color-infrared composites do not appear 


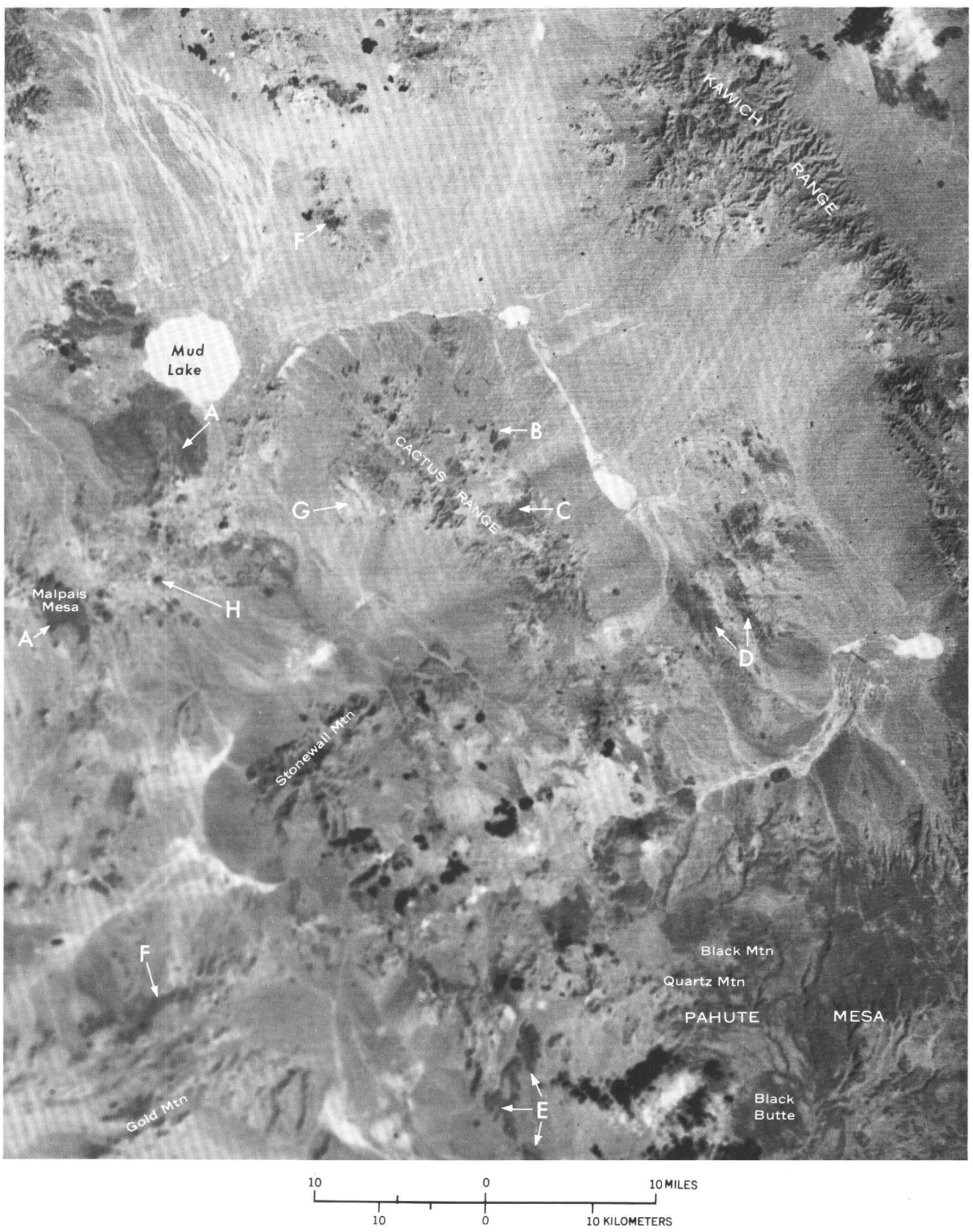


Figure 11.-Standard ERTS MSS image of the study area for band 7 (scale 1:500,000) showing some of the main physiographic features in the study area. A, andesite and basalt south-west of Mud Lake; B, three basalt outcrops east of the Cactus Range; C, mafic intrusive rock; D, hills of andesite; E, basalt flows $12 \mathrm{~km}$ south of Tolicha Peak; F, dark-appearing Precambrian and Cambrian outcrops; G, rhyolite and tuffaceous sediments on westernmost margin of the Cactus Range; $H$, basalt cap in the Goldfield mining district.

to offer a reliable means for detecting hydrothermally altered areas.

\section{STRETCHED-RATIO IMAGES}

From the previous discussions, it is clear that the spectral-reflectance differences among rock types and between altered and unaltered rocks are generally too small to be detected by visual comparison of the MSS images or through analysis of color-infrared composites. Ratioing of the spectral bands, however, provides additional means for enhancing spectral differences. Although ratioing alone is adequate to show large differences, such as those between the visible and near-infrared bands for vigorous vegetation, stretching is also necessary for adequate enhancement of the typically subtle spectralreflectance differences found among most geologic materials. The resultant images represent a visual display of the differences between the bands in slope of the spectral-reflectance curve of each geologic unit. Used in combination, ratioing and stretching offer a powerful means for discriminating rock types and alteration zones.

In the stretched-ratio images shown in figure 16, the linear stretches used have been selected to show maximum scene contrast rather than to relate film. density to the $\mathrm{DN}$ values. Hence, the ratio range selected for stretching and the amount of stretch applied to each ratio image are different. Relative spectral reflectivity, therefore, cannot be determined directly from these particular stretched-ratio images because corresponding gray levels among the images do not represent equal $\mathrm{DN}$ ratio values.

Within each of the images in figure 16, the extremes of the 16-step gray scale (not shown) represent the largest spectral-reflectivity differences. The darkest areas in each stretched-ratio image are those for which the denominator of the ratio is greater than the numerator. Conversely, the numerator is greater than the denominator for the lightest areas. For example, the largest differences in reflectance between bands for vegetation are shown in the images for ratios $5 / 6$ and $5 / 7$ (vegetation very dark) and for ratio $4 / 5$ (vegetation extremely light).

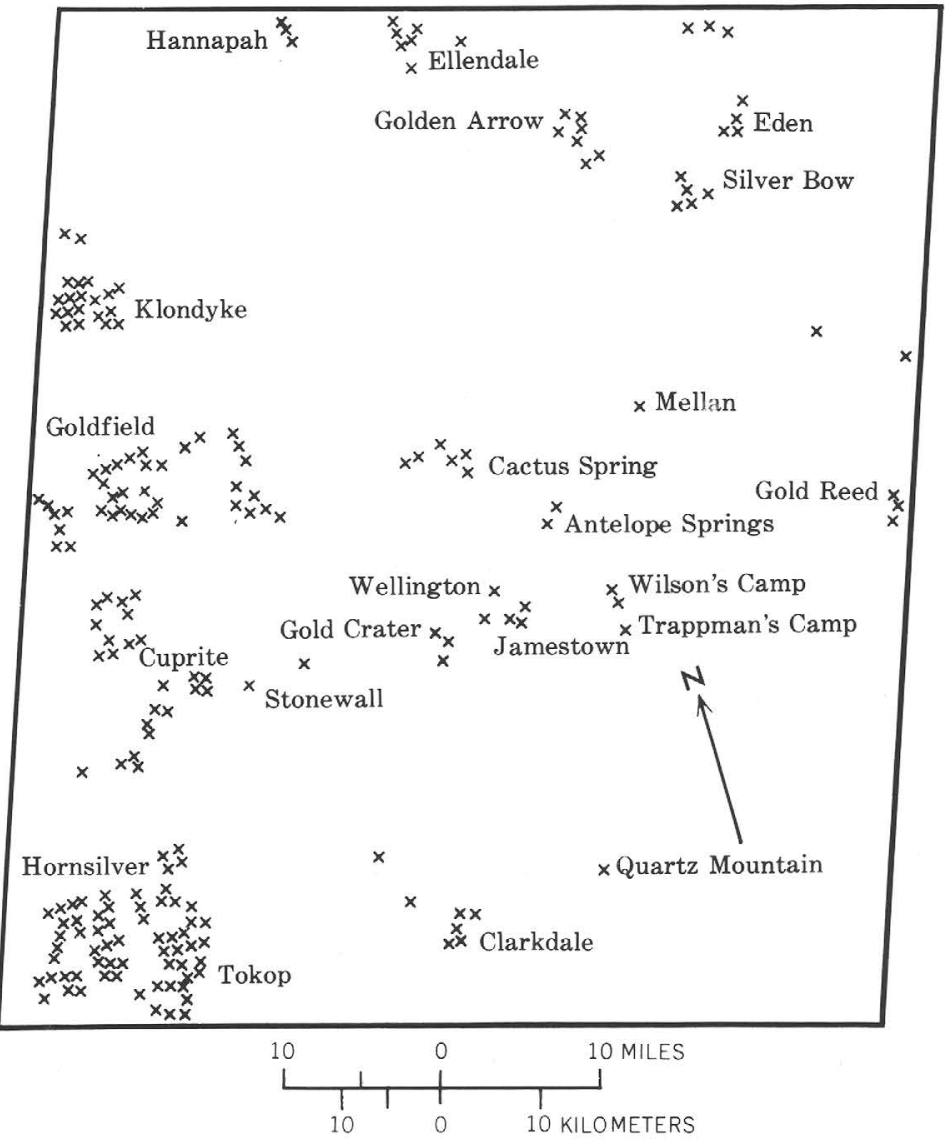

Figure 12.-Major mining districts in the study area. Data from Kral (1951), Albers and Stewart (1972), Cornwall (1972) ; J. H. Stewart (written commun., 1973) ; F. J. Kleinhampl (written commun., 1973). $\times$, approximate location of mine or prospect.

More variation within the playas is shown in the stretched-ratio images than in the previous singleband enhanced images in which no variation is apparent. Mud Lake and the southernmost playa (A) are most notable. Within all the stretched-ratio images, however, the playas can be confused with other geologic materials.

Mafic rocks ( $B$, fig. 16) appear very light and distinctive in the images for MSS $4 / 5,4 / 6$, and $4 / 7$, but discrimination is still problematic. For example, basaltic and andesitic rocks are indistinguishable, and in the image for MSS 4/5 the mafic rocks can be confused with vegetation and with the felsic rocks (C) on Pahute Mesa. Felsic rocks do not stand out in the stretched-ratio images. Most appear as medium tones of gray, although the felsic rocks on Pahute Mesa are dark in the image for MSS 5/7 and can, in this image, be discriminated from the lighter mafic rocks. 

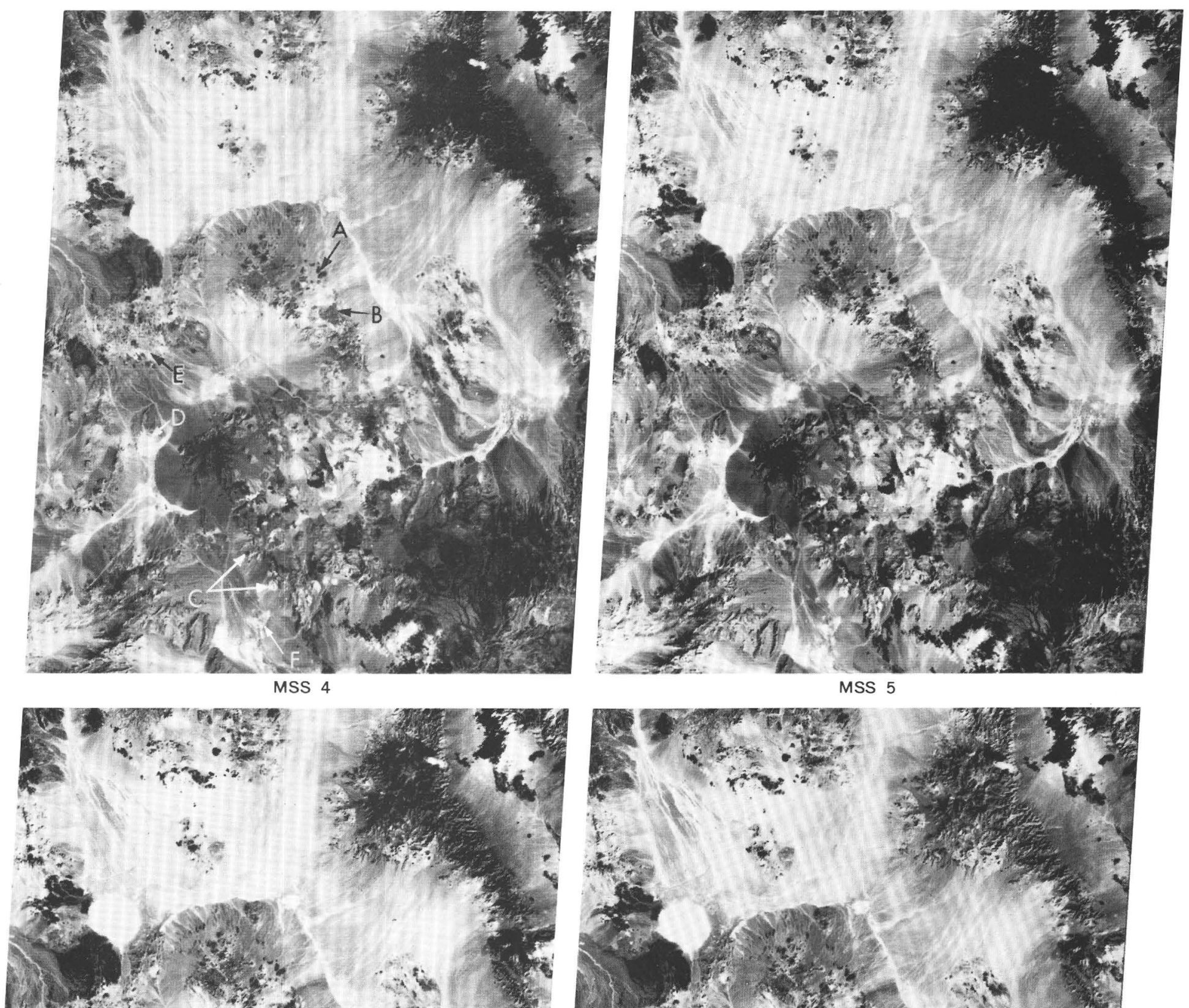

16. 3 .

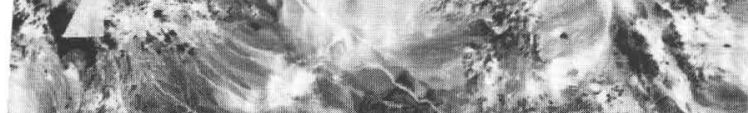

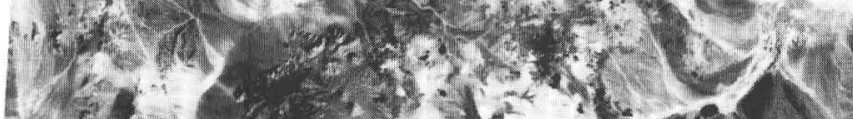

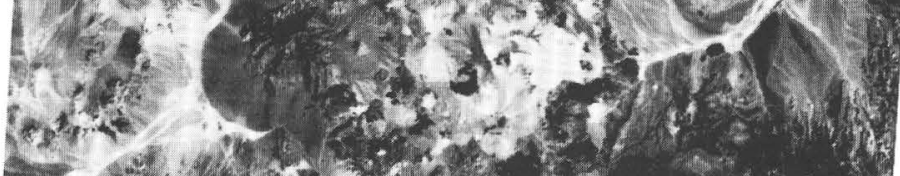
ats MSS 6

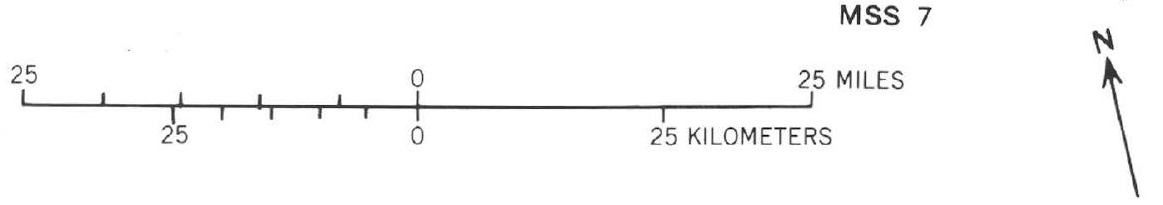


FIGURE 13.-Linearly stretched ERTS MSS images of the study area for bands 4-7 (scale 1:1,000,000). Selected DN ranges for stretch are: MSS 4, 56-108; MSS 5, 54121; MSS 6, 53-111; and MSS 7, 44-96. A, three basalt outcrops east of Cactus Range; B, mafic intrusive; C, mineralized areas southeast of Stonewall Mountain; D, Cuprite district; E, bright tuffaceous sediments south of the Goldfield district; F, bright alluvial areas.

Most of the hydrothermally altered areas are indistinct in the standard MSS and stretched MSS images and in the stretched color-infrared composites. The Goldfield mining district (fig. 12), although the largest producing district in the study area, is especially inconspicuous in these image products (figs. $10,13,15)$. In the stretched-ratio images, however, the Goldfield district shows a pattern (fig. 16, MSS $4 / 5,4 / 6,4 / 7,5 / 6$ ) that, as we will discuss next, is nearly identical with the altered area mapped by Jensen, Ashley, and Albers (1971).

Although the Goldfield district and many other known altered areas are apparent on the stretchedratio images, they cannot be discriminated from other areas with similar gray tones. The gray levels of the playas especially appear to be nearly identical with those of the altered areas.

\section{COLOR-RATIO COMPOSITES}

Color-compositing techniques offer an efficient means for combining black-and-white stretched-ratio images for discrimination of rock types. Whereas two spectrally different areas may be nearly indistinguishable in a black-and-white stretched-ratio image, proper color combination of two or more images permits discrimination on the basis of color differences. Discrimination is increased not only because information from several ratio images is combined but also because the human eye is capable of discriminating two orders of magnitude more hue values than values of gray. Color-ratio composites constitute the most useful image product for geologic analysis generated during this study.

A large number of color and ratio image combinations is possible. Ideally, selection of stretched-ratio images for compositing should be based on the spectral reflectivities of the materials of interest, but spectral data for the study area are too limited to provide an adequate basis for specific selection. Therefore, $70-\mathrm{mm}$ positive transparencies of the six stretched-ratio images were combined in a coloradditive viewer to determine the combinations most useful for discriminating the main rock types and altered areas.
Analysis of combinations of two stretched-ratio images and two color filters, from a choice of red, blue, and green, showed that no single two-component composite examined could provide adequate discrimination among major rock types, altered areas, vegetation, and playas. The most common problem involved difficulty in distinguishing the altered zones from the playas and some alluvial areas. Furthermore, in combinations in which the altered areas are detectable, some of the major rock types are not distinctive. Three-component composites (three stretched-ratio images and three color filters) have more overall discrimination potential than do the two-component composites, but discrimination between the altered areas and the playas and alluvium remains a problem.

Another color-compositing technique was tried in an effort to circumvent these problems. Color-ratio composites were prepared using diazo transparencies. Because in the diazo process the most intensely exposed parts of the image are "burned off" upon development, no color is contributed by areas that are clear (for example, $\mathrm{DN}=0$ ) in the transparency. Conversely, high film density results in intense color in the diazo-color separates. It is important to understand that the end product of this technique does not represent the reverse of the color-additive method. That is, a composite of negative transparencies made in a color-additive viewer would not be the same as a positive-transparency composite produced using the diazo process.

An optimum combination for geologic analysis of the study area was determined using the diazo process. Although all the innumerable possible color combinations and stretched-ratio-image combinations have not been evaluated, the most effective three-component color-ratio composite for discriminating between altered and unaltered areas and among the regional rock units was prepared using the following color and stretched-ratio image combination: blue for MSS 4/5, yellow for MSS 5/6, and magenta for MSS $6 / 7$. Note that these ratios involve all four MSS bands.

\section{ANALYSIS OF COLOR-RATIO COMPOSITE}

The color-ratio composite shown in figure 17 was analyzed initially by studying available geologic maps and 1:250,000-scale black-and-white photomosaics to determine which rock units should be distinguishable and to identify problem areas to be checked in the field. Several regional geologic studies have been conducted previously in this area, most notably those of Cornwall (1972), Albers and Stew- 


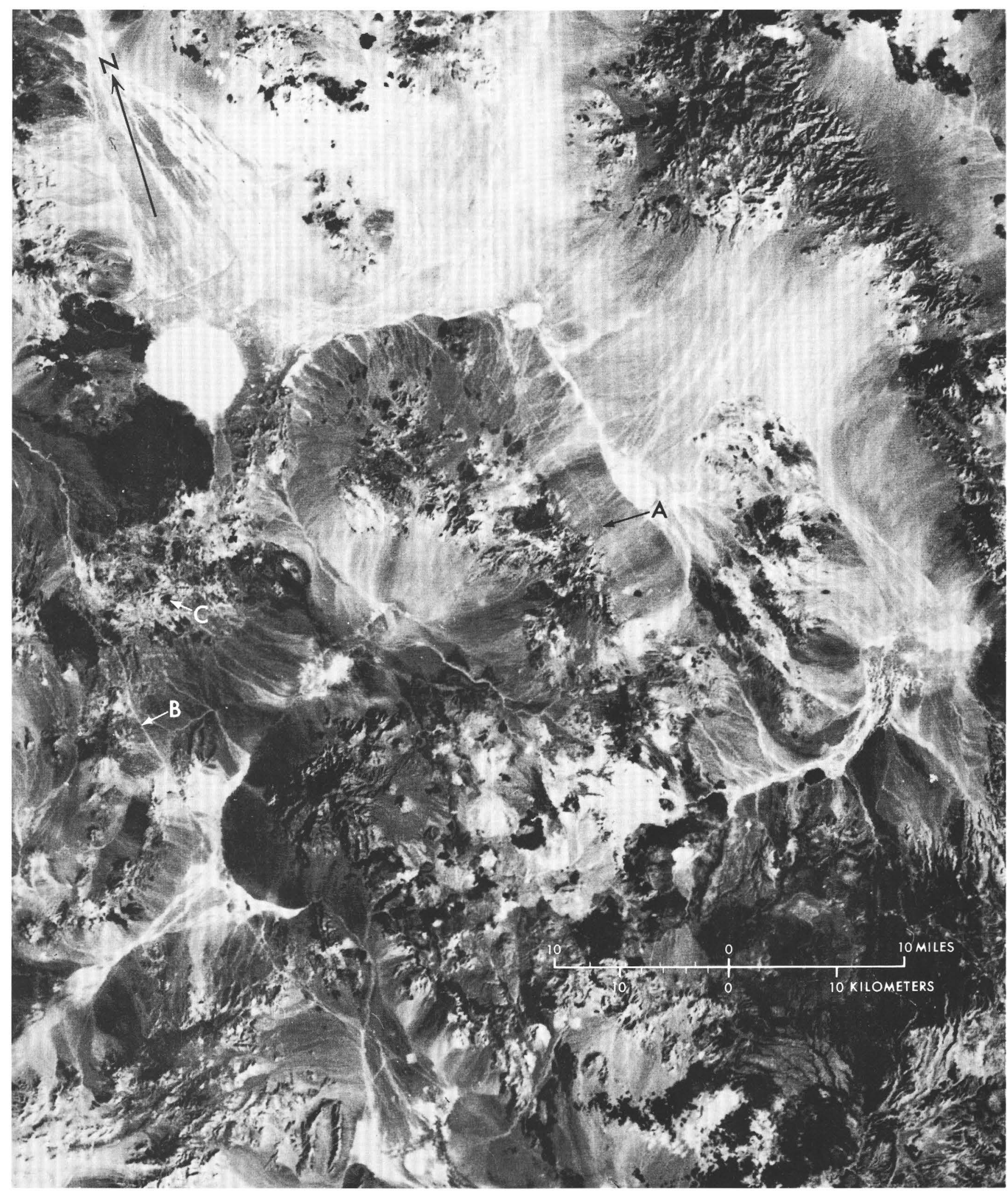

FIGURE 14.-Linearly stretched ERTS MSS image for band 7 of the study area (scale 1:500,000). Note the excellent resolution of the image as evidenced by discrimination of the secondary roads (A) and the main road (B) that passes through Goldfield and south-southeast past Stonewall Mountain. Also note the basalt cap (C) in the Goldfield mining district. 


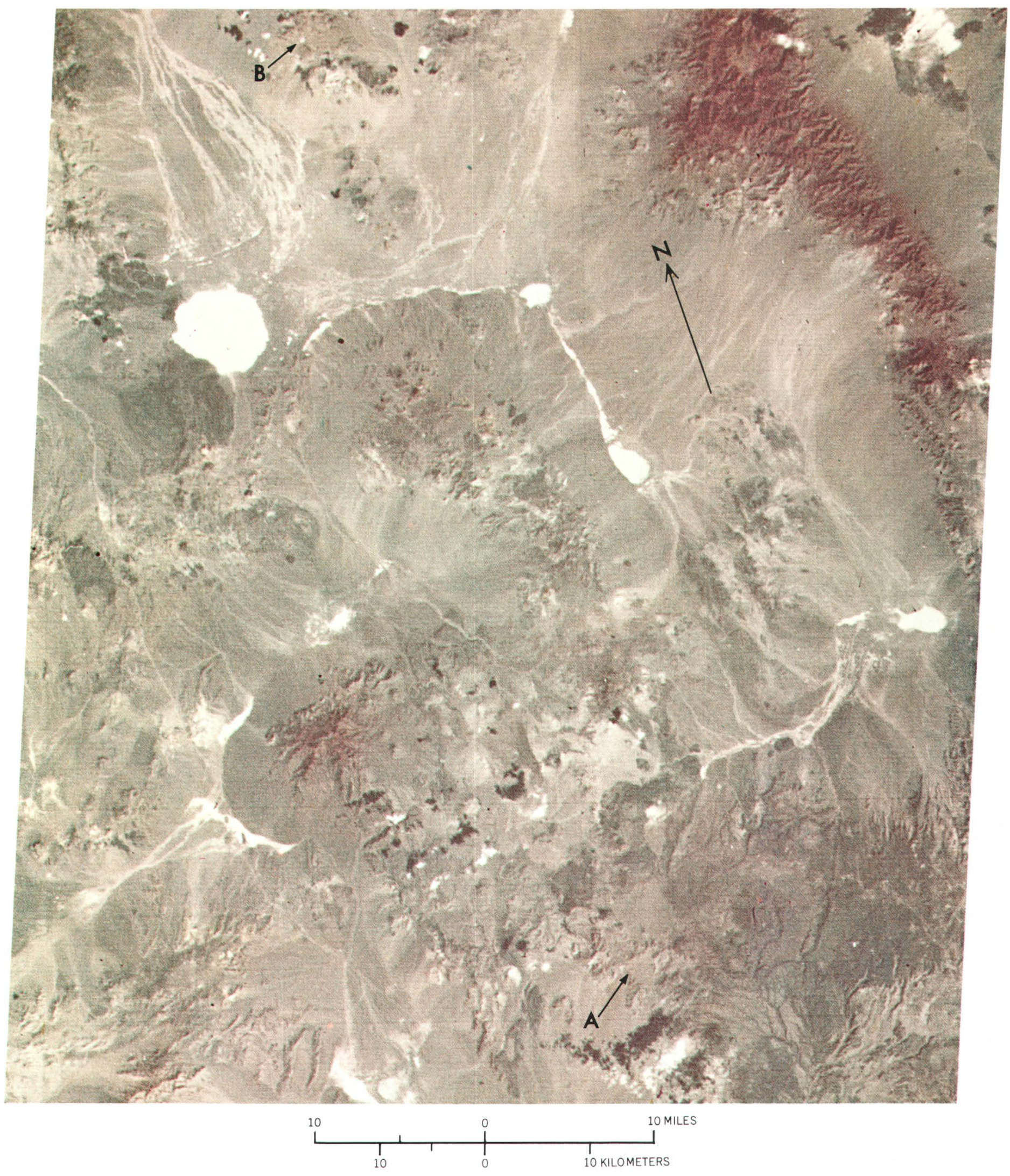

FIGURE 15.-Color-infrared composite of study area made up of linearly stretched images of ERTS MSS bands 4, 5, and 7 with blue, green, and red filters, respectively (scale 1:500,000). A and B are limonitic areas southwest of Quartz Mountain and north of Monitor Peak, respectively. Prepared by the Jet Propulsion Laboratory, Pasadena, Calif., in cooperation with the U.S. Geological Survey. 


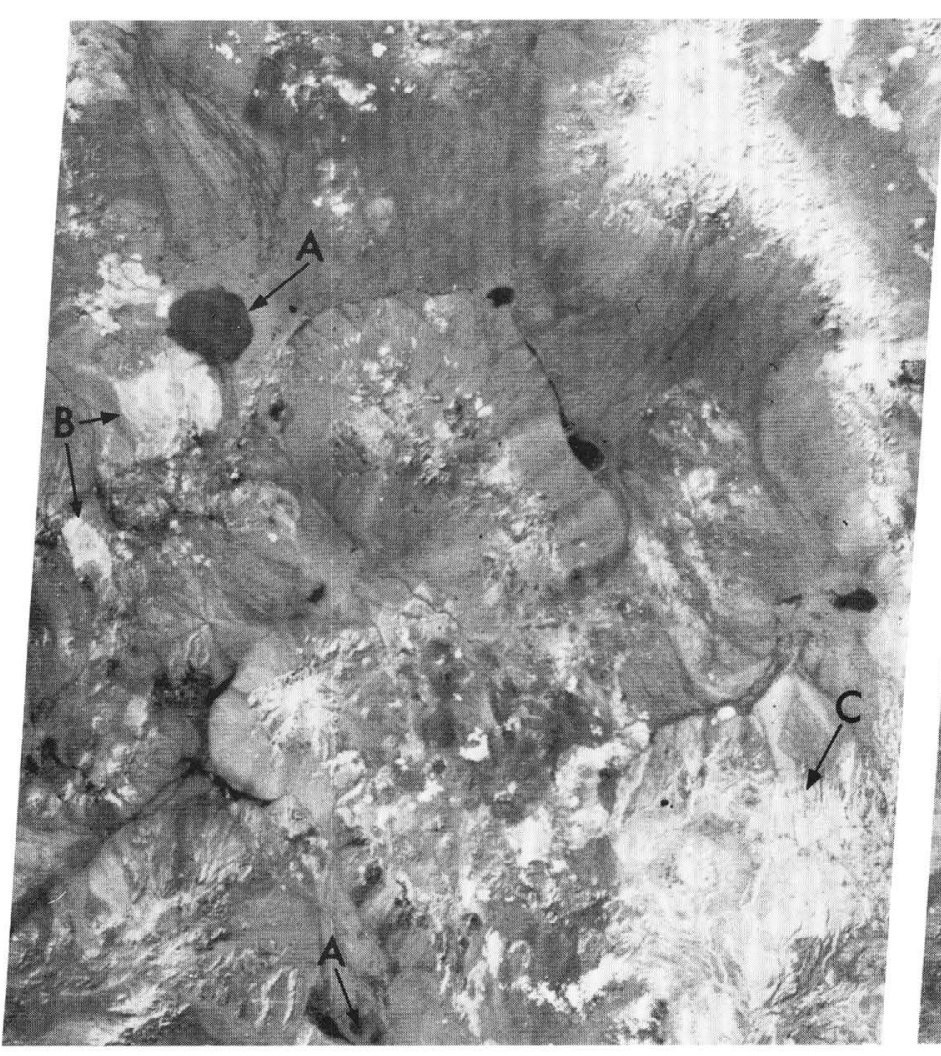

MSS $4 / 5$
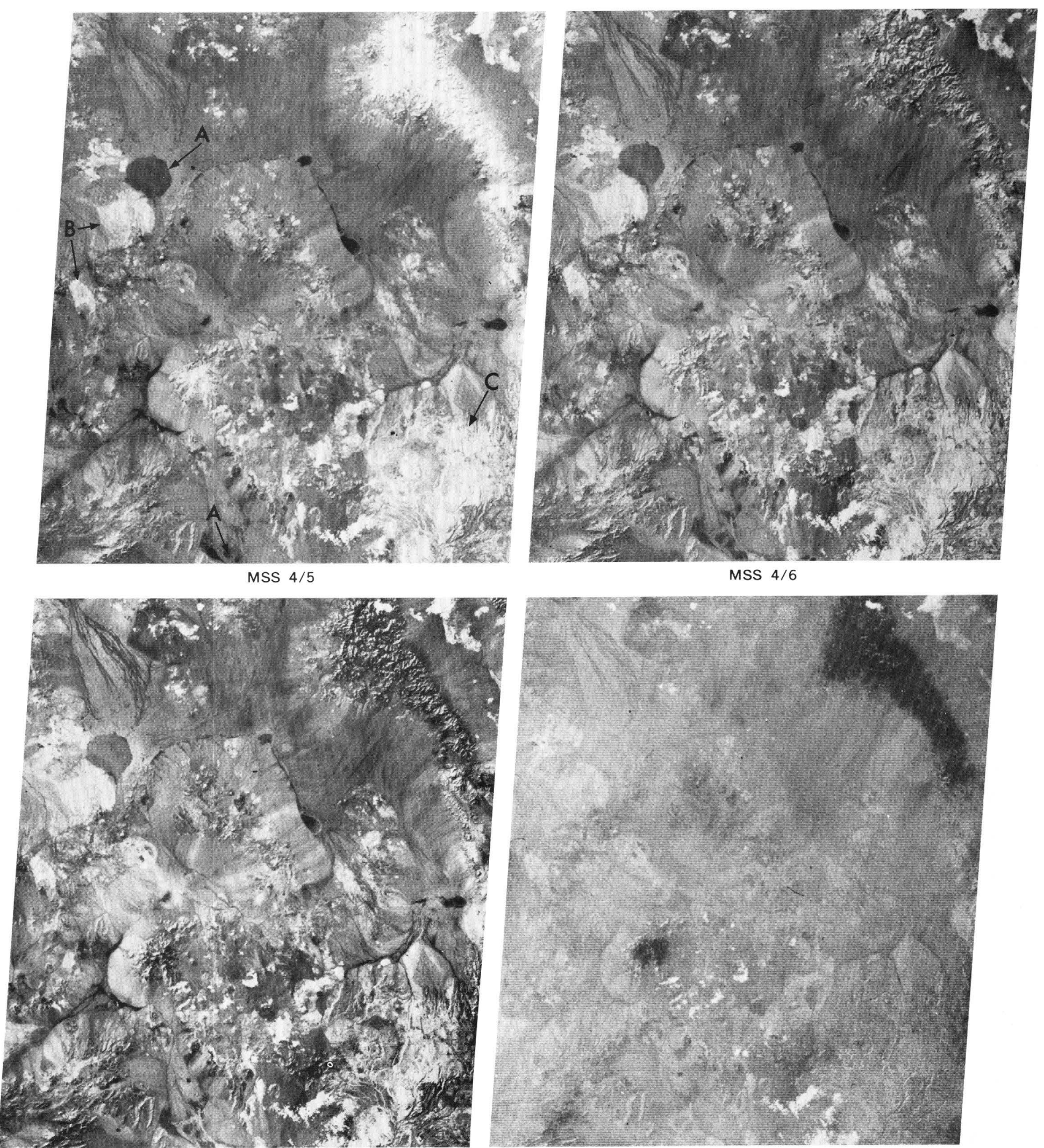

MSS $4 / 7$

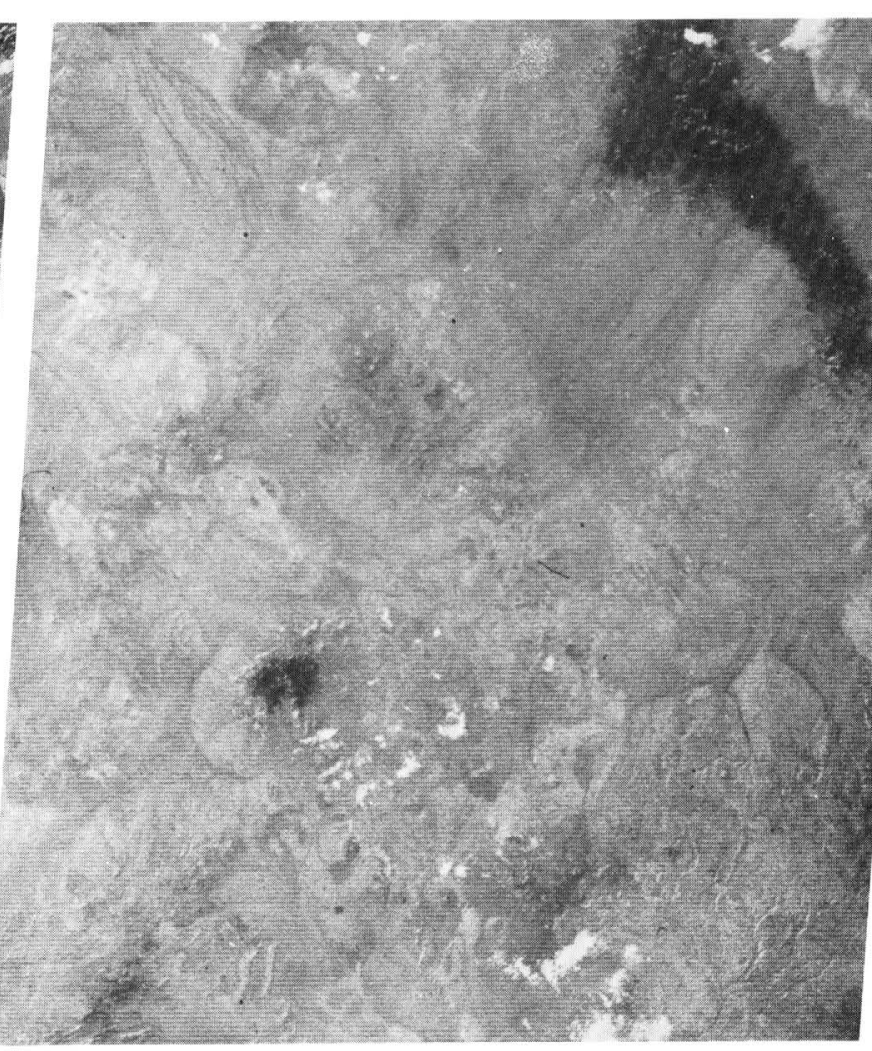

MSS $5 / 6$

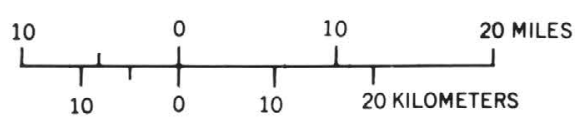



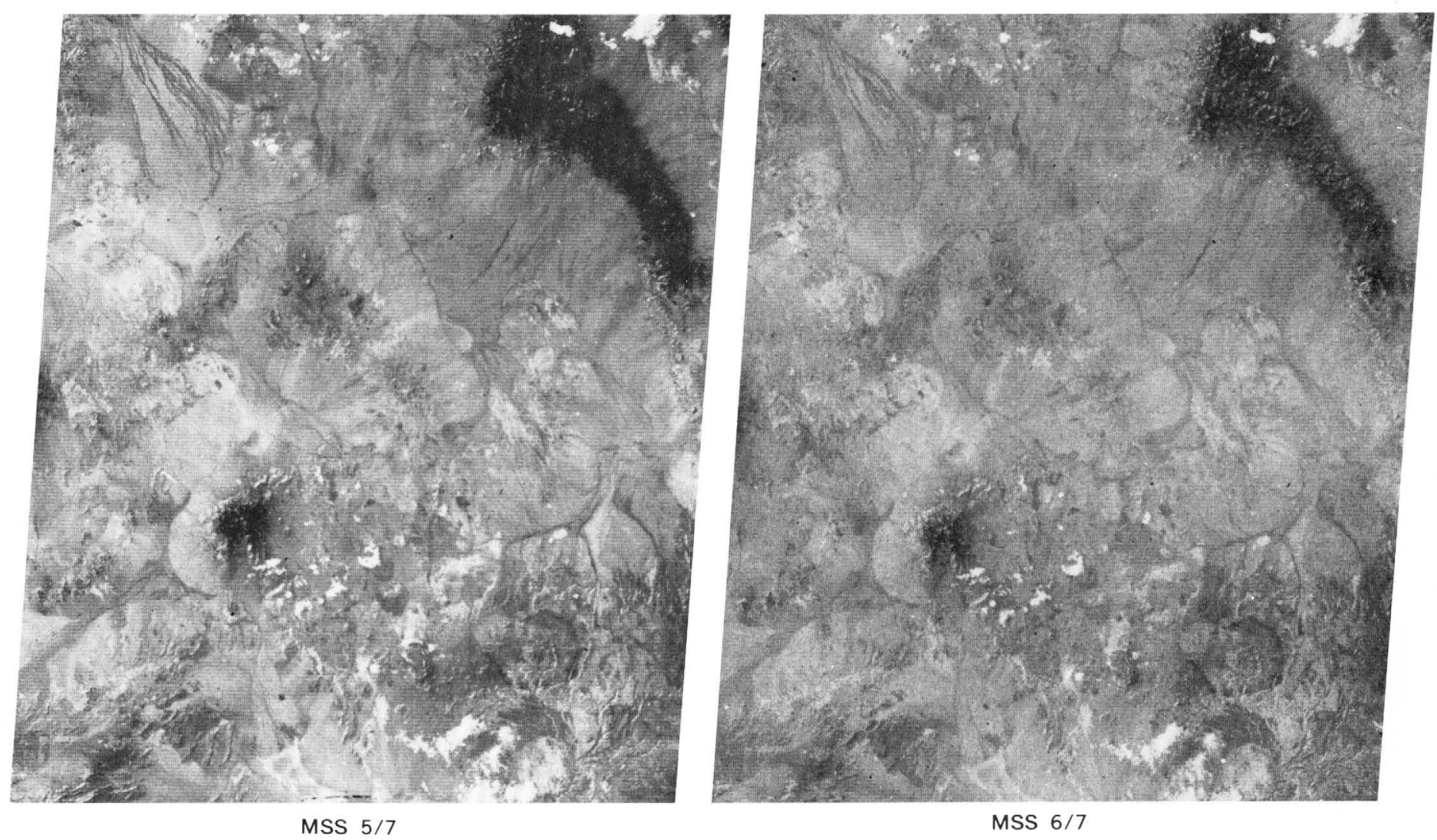

FIGURE 16.-Linearly stretched-ratio ERTS MSS images of the study area (scale 1:1,000,000) showing (A) variation in Mud Lake and southernmost playa, (B) mafic rocks, and (C) felsic rocks on Pahute Mesa. Selected ratios and DN ranges for stretch are: MSS 4/5, 116-161; MSS 4/6, 125-184; MSS 4/7, 156-222; MSS 5/6, 125-168; MSS 5/7, 152-205; MSS $6 / 7,135-178$.

art (1972), and Ekren and others (1971), but a map based on a compilation by John H. Stewart and J. E. Carlson, U.S. Geological Survey, of the State of Nevada is the most useful single map because it integrates all these previous studies (fig. 6). In addition, the original compilation scale of $1: 500,000$ is especially compatible with analysis of ERTS images. Three field evaluations, each 1 week long, were aided appreciably by overflying the area before working on the ground. Black-and-white aerial photographs at a scale of $1: 62,500$ also proved to be nearly indispensable for orientation and for distinguishing outcrops and surficial deposits.

In the color-ratio composite (fig. 17), mafic rocks are generally white, felsic rocks are pink, playas are blue, and vigorous vegetation is orange. Limonitic areas are green to yellow green, and essentially limonite-free hydrothermally altered areas range from green to brown and, more rarely, to red brown. Clouds are a dark pink brown, and cloud shadows are white; topographic shadows are also white.

Most mafic rocks can be discerned easily on the image. They appear white, usually accompanied by small patches of pink. In places, such as immediately southwest of Mud Lake (A, fig. 17), some of the pink patches associated with the white area are clearly due to the presence of tuffs and tuffaceous sediments, but in other areas the pink is probably related to residual soil formed on mafic rocks. These light-pinkcolored soils are exemplified by Malpais Mesa southwest of Goldfield (B, fig. 17), the basalt approximately $6 \mathrm{~km}$ north of Tolicha Peak (B, fig. 17), and the basalt northeast of the Kawich Range (B, fig. 17) ; they are probably felsic in composition either because the mafic minerals have been decomposed and leached, leaving a residuum consisting mainly of slightly weathered feldspar, or because a veneer of felsic eolian material overlies the basalt. Some discrepancies between the map units (fig. 6) and the color-ratio composite may be accounted for by talus deposits, as mentioned previously.

Unfortunately, several other rock units besides mafic rocks also appear white, although not consistently so. The two white spots northeast of Mud Lake (C, fig. 17) are dark-gray to black Paleozoic limestone and chert (Cornwall, 1972), and a white strip north of Gold Mountain (D, fig. 17) is dark-greengray siltstone and very fine grained quartzite of Precambrian and Cambrian age (Albers and Stewart, 1972). The eastern part of the white square area 

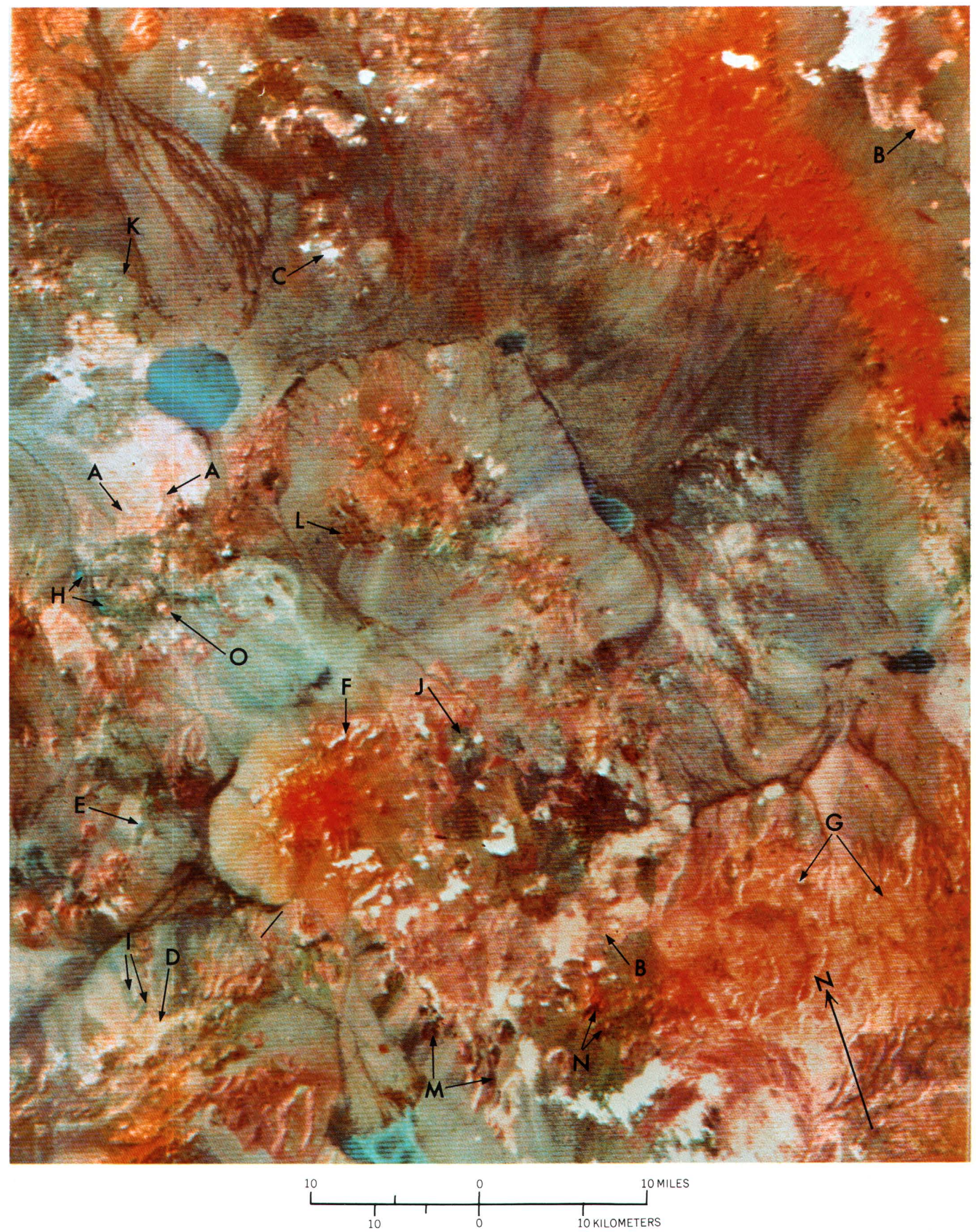
FIGURE 17.-Three-component color-ratio composite of southcentral Nevada (scale 1:500,000) made from diazo-color 4 separates showing limonitic and hydrothermally altered areas (green to brown), playas (blue), mafic rocks (generally white), felsic volcanic and intrusive rocks (pink), and vigorous vegetation (orange). Clouds are dark pink brown and cloud shadows white. Prepared from ERTS MSS data by the U.S. Geological Survey in cooperation with the Jet Propulsion Laboratory, Pasadena, Calif. EROS Data Center ID No. ER-1-CC-5000.

A, Pink patches of felsic volcanic intrusive rocks southwest of Mud Lake.

B, Light-pink-colored soils formed on mafic rocks north of Tolicha Peak and northeast of the Kawich Range.

C, Two white pre-Mesozoic elliptical features northeast of Mud Lake.

D, White pre-Mesozoic strip north of Gold Mountain.

E, Pre-Mesozoic part of the white square west of Stonewall Mountain. Western part is alluvium.

$F$, White topographic effects on northeastern part of Stonewall Mountain.

G, Orange-pink outcrops of Thirsty Canyon rhyolitic tuffs and flows, which appear dark on the other images and photographs evaluated.

$H$, Two blue areas representing mine tailings north and northeast of Goldfield.

I, Green outcrop of slightly ferruginous sandstone of the Harkless Formation.

J, Green appearing highly bleached Gold Crater area.

$K$, Green circular area of mafic intrusive body $20 \mathrm{~km}$ northwest of Mud Lake.

L, Brown area of rhyolite and tuffaceous sediments in western Cactus Range.

M, Two red-brown areas west of Stonewall Mountain.

N, Two red-brown areas near Tolicha Peak.

0 , Basalt cap mentioned in figures 8 and 14.

west of Stonewall Mountain (E, fig. 17) is part of an undifferentiated Paleozoic unit (fig. 6). The western part is presumably talus.

Additional problems in discriminating mafic rock types are the white-appearing cloud shadows and topographic effects-for example, the thin white areas northeast of Stonewall Mountain (F, fig. 17). Examination of the stretched MSS images (figs. 13 and 14), however, makes identification and discrimination of these nongeologic features straightforward.

Dark pink, brown pink, and orange pink are characteristic of felsic rocks on the image. Light vegetation cover causes the orange tone but it appears that rock reflectance, and therefore rock-type variation, can be seen if the vegetation cover is light, as on Pahute Mesa. On the other hand, where vegetation is dense, as on the Kawich Range and on Stonewall Mountain, spectral differences reflecting rock type are not recorded. These areas appear a very dark orange.
In general, the agreement between pink hues and the distribution of felsic rocks shown in the geologic map is quite striking. Most impressive is the orange-pink hue of the Thirsty Canyon tuffs and flows (Tt3 and Tr3, fig. 6; G, fig. 17). Because the surface of these rocks has a low albedo, they are easily confused with the mafic volcanic rocks both on the other images evaluated and in the field. Ratioing minimizes albedo effects, however, so that discrimination of these felsic rocks from mafic rocks is possible on the color-ratio composite. The orange pink in figure 17 indicates that the general shape of the visible and near-infrared reflectance spectra of these felsic rocks must be very similar to that of the other felsic rocks. In general, however, the older tuffs (Tt2) and flows (Tr2) are less uniform on the color-ratio composite than units Tt3 and Tr3.

Playas are easily discriminated from the altered rocks. The only blue areas in figure 17 that are not playas are two small patches representing mine tailings, north and northeast of Goldfield $(\mathrm{H}$, fig. 17). In addition, variation within and among playas is much more pronounced in the color-ratio composite than in any of the previously enhanced products. The southernmost playa and Mud Lake show the most variation, presumably because of compositional and perhaps grain-size differences.

One of the principal objectives of this study was to evaluate the potential of the MSS data for detecting hydrothermally altered areas. Although none of the previous image products seems to have much potential for discriminating altered areas, these areas can be identified with a high degree of confidence in the three-component color-ratio composite shown in figure 17. Figure 18 shows the distribution of altered outcrops based on a very general fourcolor classification of anomalous color patterns in figure 17. Black-and-white aerial photographs at a scale of $1: 62,500$ were used to exclude areas of alluvium.

In general, the green to yellow-green pattern in the color-ratio composite (fig. 17) represents predominantly limonitic outcrops. The largest anomaly is the green pattern representing the alteration zone in the Goldfield mining district (fig. 18). In fact, the agreement between the altered zone as defined by Jensen, Ashley, and Albers (1971) (fig. 18, inset) and the green pattern in figure 18 is very striking. The largest discrepancies occur in the western part of the district, where many mine dumps obscure the surface, and in the area beyond the southern border, 
which was not mapped by Jensen, Ashley, and Albers. Although the altered area consists of several different alteration products, the Goldfield district is represented by a fairly uniform green in figure 17. As mentioned previously, however, the red-brown hue of the limonite dominates the overall appearance of the complex mottled pattern (fig. 8) of the alteration zone.

On the basis of this observation and of brief evaluation of several other areas, Rowan (1973) concluded that all green areas were predominately limonitic. More detailed field examination showed, however, that included in this color pattern are two or three areas that are altered but that have little or no limonitic surface stain. For example, the Gold Crater area (J, fig. 17) is very highly bleached and has only a few limonite-stained outcrops on the lower slopes. Most of the outcrops that are green on the composite were checked in the field, and with the exception of two areas, all proved to be hydrothermally altered. One of these exceptions is the outcrop of slightly ferruginous sandstone and siltstone of the Harkless Formation (I, fig. 17), which is included in the undifferentiated Precambrian-Paleozoic map unit ( $p \in P z$ ) of figure 6. This formation occurs only in the west-central and southwestern part of the study area.

The other exception is an area that is neither limonitic nor obviously altered. The rock unit in this area, about $20 \mathrm{~km}$ northwest of the center of Mud Lake (K, fig. 17), is mapped as a Tertiary mafic intrusive body (Tmi, fig. 6). Most of the material in the crudely circular light-green area in figure 17 is alluvium derived from the intrusive body represented by darker green hills in the southwestern part of the circular area. Although a few fragments of the alluvium are limonite stained, the greenishgray outcrops appear on the ground to be generally free from ferric iron surface stains. This still enigmatic area will be the subject of future coordinated petrographic and spectral analyses.

Most of the other altered areas are dark green to brown in the color-ratio composite (figs. 17 and 18). The dark-green areas, all of which were examined in the field, are confined to the southern half of the area. The rocks themselves in these areas are typically pink to red, tan, yellow, and gray mottled, altered Tertiary volcanic rocks. The dark green in figure 17 represents both limonitic and limonite-free altered areas, although less limonite is generally present than in the light-green category.

Brown areas in the color-ratio composite are more numerous than dark-green areas and have not been examined as thoroughly. The materials in the brown areas appear to be made up of light-colored Tertiary volcanic rocks, some of which are glassy and pumiceous. Limonite-free areas predominate, but some limonite may be present. In the Silver Bow district, the only brown area checked in detail on the ground, hydrothermal alteration is evident. Other brown areas checked from the air, such as those on the southeastern and southwestern margins of the Kawich Range, are light-colored volcanic rocks, but the presence of hydrothermal alteration could not be determined. Ekren and others (1971), however, stated that the light colors of the tuffaceous sediments in the large brown area in the western Cactus Range (L, fig. 17) typify zeolitized, silicified, or argillized rocks.

Several dark-green to brown areas proved to be alluvium that is limonite stained. Weathering of the many exposed surfaces of the small fragments results in the formation of abundant ferric oxide. The MSS, therefore, records the characteristic spectrum of limonite (Hunt and others, 1971a; Rowan, 1972) for these weathered but not hydrothermally altered materials.

A few altered areas appear red brown in the colorratio composite. The two areas west of Stonewall Mountain (M, fig. 17) and the two areas near Tolicha Peak (N, fig. 17) were examined in the field, and in all four places the rocks are nearly white silica-rich Tertiary volcanic rocks with no limonite present. The rocks west of Stonewall Mountain have been lightly altered by epithermal activity to very fine grained silica, whereas the Tolicha Peak volcanic rocks are very glassy tuffs without any obvious hydrothermal alteration.

Assessment of the color-ratio composite indicates that green, dark green, brown, and red brown, which seem to represent, in that order, predominantly limonite-stained rocks to highly bleached and argillized rocks, are generally indicative of hydrothermal alteration. Comparison of the areal distribution of mining districts (fig. 19) and the color anomalies (fig. 18) substantiates this conclusion, even though figure 19 represents only a general map of the mines and prospects. Some mines and prospects were omitted necessarily in areas of high mine density.

Most of the major mining districts-Goldfield, Cactus Spring, Antelope Springs, Gold Reed, Gold Crater, Wilson's Camp, Trappman's Camp, and Wellington-have concentrations of green to yellow green and dark green. A few green areas apparently do not have mines or prospects, although they consistently represent areas of altered rocks. Brown and red brown dominate the Silver Bow, Golden Arrow, Cuprite, and Hannapah districts, in some of which hydrothermal alteration is evident. Several brown and red-brown areas have no evidence of mining, al- 
TABLE 1.-Ratios calculated for MSS bands for selected mafic and felsic rocks and

\begin{tabular}{|c|c|c|c|c|}
\hline Sample & Number & MSS 4/5 & MSS $5 / 6$ & MSS $6 / 7$ \\
\hline \multicolumn{5}{|c|}{ Mafic rocks } \\
\hline Basalt & 13 & 1.05 & 1.03 & 1.06 \\
\hline Gabbro & 9 & 1.07 & 1.01 & .99 \\
\hline Peridotite & 8 & 1.01 & 1.01 & 1.05 \\
\hline Serpentinite & 15 & 1.04 & 1.05 & 1.07 \\
\hline \multicolumn{5}{|c|}{ Felsic rocks } \\
\hline Rhyolite (pink) & 12 & 0.79 & 0.92 & 0.96 \\
\hline Rhyolite (gray) & 4 & .96 & .96 & .98 \\
\hline Granite & 14 & .89 & .94 & .91 \\
\hline Granite & $\overline{5}$ & .97 & .98 & .92 \\
\hline Granodiorite & 2 & .92 & .94 & .97 \\
\hline \multicolumn{5}{|c|}{ Alteration minerals } \\
\hline Limonite (goethitic) & $\ldots$ & 0.61 & 0.72 & 0.94 \\
\hline Limonite (hematitic) & $\ldots$ & .49 & .85 & .95 \\
\hline Jarosite & $\ldots$ & .78 & .99 & 1.27 \\
\hline Montmorillonite & $\ldots$ & .65 & .84 & 1.07 \\
\hline Alunite & -- & .66 & .88 & .97 \\
\hline Kaolinite & - & .93 & .98 & .99 \\
\hline
\end{tabular}

though they are generally concentrated in areas of past mining activity. Considerably more work needs to be done to evaluate all the brown and red-brown areas fully.

Two mining districts, Eden and Stonewall, are noteworthy because anomalous colors are not present (figs. 17, 19). In these districts, the spectral-reflectivity information is probably obscured by vegetation and topographic shadows, respectively, but there is little surface indication of alteration in the vicinity of the Stonewall district (R. P. Ashley,written commun., 1973). Anomalous colors are not shown in figure 18 for the Mellan district because the area that appears green in figure 17 is mainly alluvium. The southwestern part of the area is also important because, although many mines are present (fig. 19), the areal density of colors indicative of hydrothermal alteration is obviously lower than in most of the other mining districts. The main geological difference between this general area and the rest of the anomalously colored areas appears to be the prevalence of Mesozoic and Precambrian-Paleozoic rocks. The ore bodies occur as vein deposits associated with the Mesozoic intrusive rocks in this area, and the surface area of alteration is very much smaller than in the altered Tertiary volcanic rocks. Hence, higher spatial resolution may be needed to detect the alteration in an area such as this.

The general correlation between the color anomalies (fig. 18) and the known mining-district locations (fig. 19) indicates that color-ratio composites should be especially valuable as a means of reconnaissance mapping for mineral exploration in wellexposed areas. Color-anomaly maps such as figure 18 can be used for selection of specific targets for detailed geologic, geochemical, and geophysical analyses.

\section{DISCUSSION}

One of the ultimate objectives of this investigation is to derive quantitative spectral-reflectivity information from the MSS images and to use these data for making estimates of the bulk composition of surface materials. Although this objective is not presently feasible because of inadequate calibration data, the spectral differences seen as color variations in the color-ratio composite (fig. 17) can be evaluated qualitatively by considering iaboratory spectra that appear to be reasonably representative of the surface materials.

As discussed previously, visible and near-infrared reflectance spectra for mafic and felsic rocks (fig. 2) have generally different shapes. Although data for only a few of the rock types present in the study area are included in figure 2 , a general idea of the anticipated differences can be gained through comparison of these spectra. A useful method for making such comparisons is examining calculated ratio values based on the width of the MSS bands used in processing the color-ratio composite (MSS 4/5, 5/6, and $6 / 7$ ). These ratio values are not representative of the absolute MSS values because of undetermined effects of the solar spectrum and of atmospheric variations, but the calculated ratio values can be useful for comparative purposes. In general, ratios for the felsic rocks are less than unity, whereas the mafic rock ratios are greater than unity (table 1 ). Comparison of the basalt with the two rhyolite spectra shows that the ratios for basalt are approximately 7-12 percent higher, except in the MSS $4 / 5$ ratio for the pink rhyolite (table 1 ) where the difference is about 25 percent. These low percentage values attest to the subtlety of the spectral differences among even very different rock types. It is 


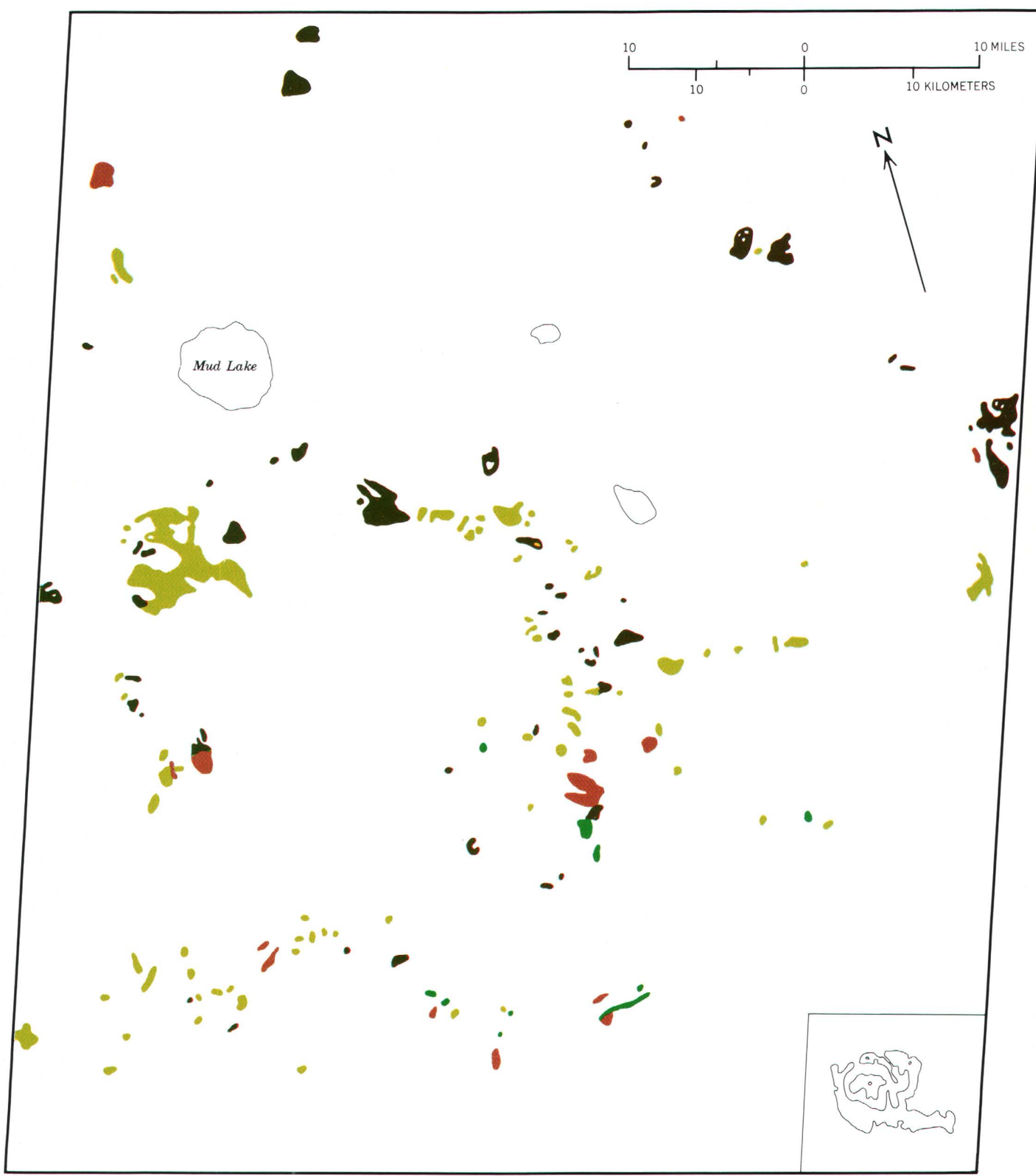

ALTERED AREAS IN STUDY AREA

FIGURE 18.-Distribution in the study area of anomalous color patterns, classified by four colors-green, dark green, red brown, and brown (from fig. 17). These color patterns represent altered outcrops. Inset is an alteration map of the Goldfield district by Jensen, Ashley, and Albers (1971) at the same scale. 


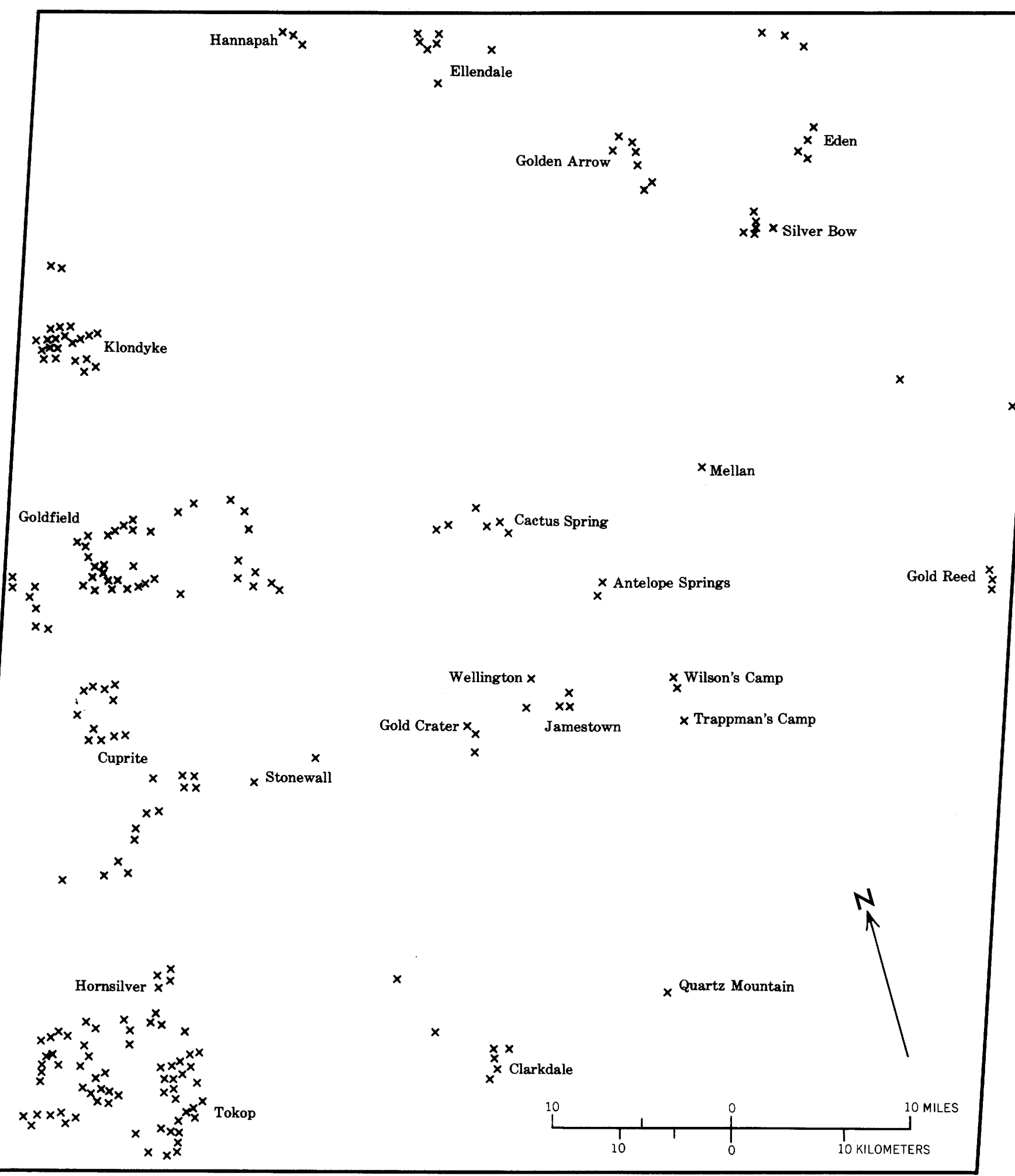

FiguRE 19.-Major mining districts in the study area (scale 1:500,000). From Kral (1951), Albers and Stewart (1972), Cornwall (1972), J. H. Stewart (written commun., 1973), F. J. Kleinhampl (written commun., 1973). $X$, approximate location of mine or prospect. 
not surprising, therefore, that some form of computer processing is necessary to enhance the spectral signatures of mafic and felsic rocks in the standard ERTS images. Additional computer processing, perhaps using cube-root stretch of the ratio values to increase scene contrast in the dark areas in the stretched-ratio images, might permit further discrimination between, for example, basalts and andesites.

Evaluation of the altered areas is more difficult because spectroradiometric studies have not been conducted on altered rocks. A few laboratory spectra, however, have been published for most of the main minerals that constitute the Goldfield alteration zone, including limonite, montmorillonite, alunite, kaolinite, and jarosite (fig. 20). Comparison

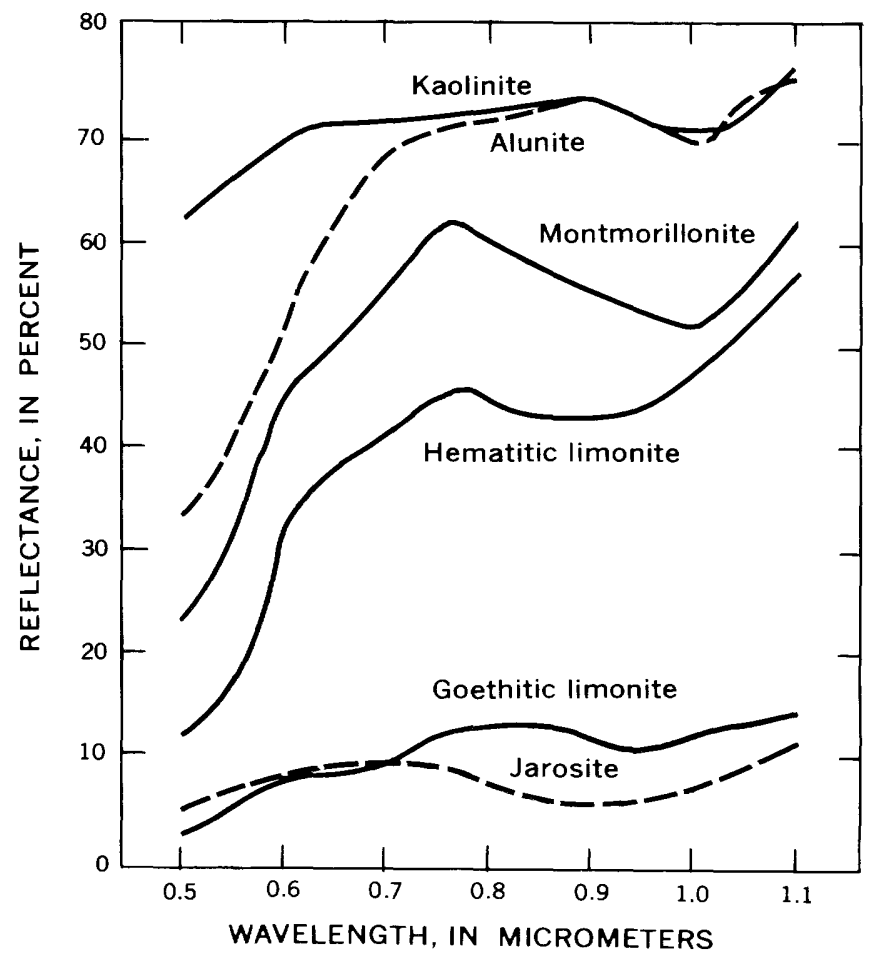

FIGURE 20.-Reflectance spectra for alteration minerals. Data for montmorillonite and kaolinite from Hunt and Salisbury (1970), alunite and jarosite from Hunt, Salisbury, and Lenhoff (1971b), goethitic limonite from Rowan (1972), hematitic limonite obtained in place at Goldfield (A. F. H. Goetz, written commun., 1973).

of the ratios calculated for these spectra and for the mafic rocks (table 1) shows that the MSS $4 / 5$ values for the alteration products are significantly lower than those for mafic rocks and that the MSS 5/6 ratios are slightly lower. Therefore these alteration products should be very distinctive where they occur in areas underlain by mafic rocks. Comparison with the felsic-rock ratios indicates that geothitic and hematitic limonite, alunite, and montmorillonite should be distinguishable from felsic rocks because of their lower MSS 4/5 ratios and somewhat lower MSS 5/6 ratios. The jarosite MSS $4 / 5$ ratio is only slightly lower than the felsic-rock ratios; however, the MSS 6/7 ratio for jarosite is markedly higher than the largest value for the felsic rocks, so this ratio could be used for discrimination purposes. The ratios shown in table 1 for kaolinite resemble those for the felsic rocks of figure 2 , and it is doubtful that such small differences could be distinguished in a color-ratio composite. However, as Ashley (1970) pointed out, illite and alunite are associated with kaolinite in the more intensely altered zone at Goldfield. Both of these minerals might, as the uniform green of the color-ratio composite at Goldfield indicates, subdue the effects of the kaolinitic spectral reflectivity and result in low ratios.

Although altered and unaltered rocks are discriminated with a high level of confidence in the color-ratio composite, limonitic and limonite-free hydrothermally altered areas do not appear to be distinguishable at this stage of the analysis. Although this distinction does not appear to be economically important in the study area because metallization occurs in both types of areas, it could be important in areas where limonite is not particularly diagnostic of hydrothermal alteration. The calculated ratios in table 1 suggest that the MSS $4 / 5$ ratio should provide the best opportunity for distinguishing bleached argillized and limonitic altered rocks, especially where the limonite is hematitic rather than goethitic. In addition, higher spectral resolution and bands at longer wavelengths, such as those provided by the NASA Skylab multispectral scanner (S192), should significantly aid in discriminating these materials and in estimating the mineralogical makeup of the surface materials.

The above discussion illustrates the critical need for a clearer definition of the relationship between mineralogical composition and visible and nearinfrared spectral reflectivity of altered and unaltered rocks. Ideally, in situ spectroradiometric measurements, at several scales and coordinated with detailed sampling for subsequent mineralogical analysis, should be made in a variety of geologic settings and environmental conditions. An important use for these in situ measurements is formulation of spectral-reflectivity standards that take into account varying surface-state conditions. The standard areas should be of different albedos but nearly uniform 
over large areas, and the spectral information should be collected at the same time as the satellite overflight so that atmospheric conditions are similar. Spectral-reflectance standards acquired in this fashion could be used to normalize all the $\mathrm{DN}$ values in the MSS images, provided that atmospheric transmission and path-radiance are uniform over the run. Then quantitative spectral-reflectivity information could be extracted directly from the DN values for any surface unit.

\section{SUMMARY AND CONCLUSIONS}

The results of this study show that most of the major rock units and altered and unaltered areas in the study area can be separated on the basis of visible and near-infrared spectral-reflectivity differences recorded from satellite altitude. Because these differences are mainly due to slight variations in the slopes of the spectra, they are not detectable through visual or optically assisted techniques. Digital ratioing of the MSS bands and subsequent stretching to increase the contrast are necessary to enhance these differences. Although the basic spectral information is contained in the stretched-ratio images, colorratio composites, especially combinations of three ratio images, appear to be the best means of display for geologic visual interpretation as an aid in mineral-resources exploration and regional geologic mapping.

For discrimination of hydrothermally altered areas and of regional rock (and soil) units in the study areas, the optimum color-ratio composite appears to be a combination of diazo-color transparencies having the following ratio images and colors: blue for MSS 4/5, yellow for MSS 5/6, and magenta for MSS 6/7. In this composite (fig. 17), mafic rocks are generally distinguishable from felsic rocks despite their similar albedos in some places. Details within playas are best seen in the color-ratio composite. Some of the most important practical limitations, however, include erroneous identification of basalt as felsic rocks where soil overlies areas of the basalt, and lack of discrimination thus far of basaltic and andesitic rocks.

Hydrothermally altered areas appear as anomalous color patterns (fig. 17) within the volcanic rocks on the color-ratio composite. Comparison of known mining-district locations and clusters of anomalous colors, ranging from green and dark green to brown and red brown, shows good agreement in the widespread Tertiary volcanic rocks. In the Goldfield mining district, for example, very striking agreement was found between the anomalous green pattern and the map of the altered area by Jensen, Ashley, and Albers (1971). However, the density of anomalies compared with that of the mines is not as high in the southwestern part of the study area where the alteration and mineralization are associated with intrusion of pre-Mesozoic rocks rather than with the Tertiary volcanic rocks. In spite of the few discrepancies, the color-anomaly map showing the distribution of altered areas (fig. 18) should be very useful for identifying sites where detailed geological, geochemical, and geophysical analyses should be made during mineral-resources exploration.

In general, the green to dark-green color pattern in this color-ratio composite represents predominantly limonitic areas, which except for two cases, are hydrothermally altered. All green areas in the composite are not limonitic however. Several green areas, as is well illustrated in the Gold Crater area, are essentially limonite-free argillized volcanic rocks. Red-brown areas in the color-ratio composite commonly appear to be silica-rich light-colored volcanic rocks. In the Cuprite district, the red-brown color correlates very well with the silicified zone in which hydrothermal alteration has taken place, but the red-brown areas near Tolicha Peak are very glassy tuffs without any obvious hydrothermal alteration. Brown areas, though studied in less detail than the other color anomalies, generally seem to represent light-colored volcanic rocks, with hydrothermal alteration present at least in the Silver Bow district. The presence of hydrothermal activity in other brown areas could not be determined at this time.

Although adequate spectroradiometric measurements are not yet available for defining the relationships between the mineralogical composition and spectral reflectivity of the surface materials, analysis of laboratory spectra suggests that ratio differences of 7-12 percent between the felsic and mafic rocks may be shown in the color-ratio composite. Comparison of the ratios calculated for unaltered rocks and alteration minerals common to the Goldfield district shows that in general the altered rocks should be discriminable, especially in the MSS $4 / 5$ ratio. The inability to distinguish between limonitic and limonite-free hydrothermally altered areas is believed to be due to the similar general shapes of limonite and nonferrous alteration minerals and to the low spectral resolution and absence of spectral bands beyond $1.1 \mu \mathrm{m}$ in the MSS. Higher spectral resolution images of the area, especially recorded 
beyond $1.1 \mu \mathrm{m}$, should provide adequate discrimination between limonite and the nonferrous alteration minerals. Additional computer processing of the MSS data may also aid in distinction of materials.

Because the studies described here have been directed towards areas of outcrop, surficial deposits have received very little attention; even a cursory examination of the color-ratio composite, however, shows considerable spectral information for these materials, which should be useful for study of these areas. An interesting result pertaining to these surficial deposits is that a thin coating of ferric iron apparently forms on the fragments derived through weathering of some felsic rocks, thereby causing the anomalous green color on the color-ratio composite in some alluvial areas. The exclusion of these areas from the color-anomaly map is important because they are not hydrothermally altered.

Refinement and further testing of these computerprocessing and geologic-interpretation techniques are necessary for realizing the full potential in geologic exploration. An especially critical need at this stage is for in situ spectroradiometric measurements coordinated with detailed sampling for subsequent mineralogical analysis in a variety of geologic and environmental conditions.

Additional computer-processing techniques that deserve consideration include cluster analysis and automatic classification. However, the advantage of interpreting a color-ratio composite over using a pure classification scheme, such as the LARSYS method (Landgrebe, 1971), is that the analyst can take into account many other factors, such as the distinction between outcrop and surficial deposits, before delineating boundaries among units. An additional advantage of the ratio method used in this study is that computer-processing time is reduced by a factor of 100 or more below the time for the LARSYS classification scheme, with an accompanying substantial cost saving. Nevertheless, consideration should be given to such classification schemes as well as to both supervised and unsupervised clusteranalysis techniques.

Although many questions have been left unanswered by this report, the results indicate that geologic exploration can benefit substantially by the use of digital computer processing of visible and nearinfrared MSS images. Limitations imposed by the low spatial and spectral resolutions of the ERTS-1 MSS must be overcome in subsequent satellite systems so that the results can be applied to larger scale problems. In the meantime, in order to define the effects of spatial resolution and intervening at- mosphere, visible and near-infrared spectral data should be collected from aircraft platforms, processed in a manner similar to that applied to these ERTS images, and analyzed in conjunction with existing geologic maps, field study, and spectralreflectivity information.

\section{REFERENCES CITED}

Albers, J. P., and Cornwall, H. R., 1968, Revised interpretation of the stratigraphy and structure of the Goldfield district, Esmeralda and Nye Counties, Nevada [abs.]: Geol. Soc. America Spec. Paper 101, p. 285.

Albers, J. P., and Kleinhampl, F. J., 1970, Spatial relation of mineral deposits to Tertiary volcanic centers in Nevada: U.S. Geol. Survey Prof. Paper 700-C, p. C1-C10.

Albers, J. P., and Stewart, J. H., 1972, Geology and mineral deposits of Esmeralda County, Nevada: Nevada Bur. Mines and Geology Bull. 78, 80 p.

Ashley, R. P., 1970, Evaluation of color and color infrared photography from the Goldfield mining district, Esmeralda and Nye Counties, Nevada: U.S. Geol. Survey open-file report, $36 \mathrm{p}$.

Ashley, R. P., and Keith, W. J., 1973, Geochemistry of the altered area at Goldfield, Nevada, including anomalous and background values for gold and other ore metals: U.S. Geol. Survey open-file report, $117 \mathrm{p}$.

Bancroft, G. M., and Burns, R. G., 1967, Interpretation of the electronic spectra of iron in pyroxenes: Am. Mineralogist, v. 52 , nos. $9-10$, p. 1278-1287.

Billingsley, F. C., and Goetz, A. F. H., 1973, Computer techniques used for some enhancement of ERTS images, in Friden, S. C., and others, compilers and editors, Symposium on significant results obtained from the Earth Resources Technology Satellite-1. Volume I-Technical Presentations, Section 13: U.S. Natl. Aeronautics and Space Admin. SP-327, p. 1159-1168.

Billingsley, F. C., Goetz, A. F. H., and Lindsley, J. N., 1970, Color differentiation by computer image processing: Photog. Sci. and Engineering, v. 14, no. 1, p. 28-35.

Cornwall, H. R., 1972, Geology and mineral deposits of southern Nye County, Nevada: Nevada Bur. Mines Geol. Bull. 77, 45 p.

Ekren, E. B., Anderson, R. E., Rogers, C. L., and Noble, D. C., 1971, Geology of northern Nellis Air Force Base Bombing and Gunnery Range, Nye County, Nevada: U.S. Geol. Survey Prof. Paper 651, 91 p.

Goetz, A. F. H., 1974, Quality and use of ERTS radiometric information in geologic applications: Ann. Conf. Application Remote Sensing Arid Land Resources and Environment 4th, Tucson, Ariz. Nov. 14-16, 1973. (In press).

Goetz, A. F. H., Billingsley, F. C., Yost, E., and McCord, T. B., 1971, Apollo 12 multispectral photography experiment, in Levinson, A. A., ed., Proceedings of the Second Lunar Science Conference, Houston, Texas, January 11-14, 1971: Cambridge, Mass., MIT Press, v. 3, p. 2301-2310 (Geochim, et Cosmochim, Acta, Supp. 2).

Harvey, R. D., and Vitaliano, C. J., 1964, Wall-rock alteration in the Goldfield district, Nevada: Jour. Geology, v. 72 , no. 5 , p. 564-579.

Hunt, G. R., and Salisbury, J. W., 1970, Visible and nearinfrared spectra of minerals and rocks-I. Silicate min- 
erals: Modern Geology, v. 1, no. 4, p. 238-300.

Hunt, G. R., Salisbury, J. W., and Lenhoff, C. J., 1971a, Visible and near-infrared spectra of minerals and rocksIII. Oxides and hydroxides: Modern Geology, v. 2, no. 3, p. 195-205.

$1971 \mathrm{~b}$, Visible and near-infrared spectra of minerals and rocks-IV. Sulphides and sulphates: Modern Geology, v. 3, no. 1, p. 1-14.

1973a, Visible and near-infrared spectra of minerals and rocks-VII. Acidic igneous rocks: Modern Geology, v. 4 , p. $217-224$.

$1973 \mathrm{~b}$, Visible and near-infrared spectra of minerals and rocks-VI. Additional silicates: Modern Geolog:y, v. 4 , p. 85-106.

1974a, Visible and near-infrared spectra of minerals and rocks-VIII. Intermediate igneous rocks: Modern Geology (In press).

$1974 \mathrm{~b}$, Visible and near-infrared spectra of minerals and rocks-IX. Basic and ultrabasic igneous rocks: Modern Geology (In press).

Jensen, M. L., Ashley, R. P., and Albers, J. P. 1971, Primary and secondary sulfates at Goldfield, Nevada: Econ. Geology, v. 66, p. $618-626$.

Kral, V. E., 1951, Mineral resources of Nye County, Nevada: Nevada Univ. Bull., v. 45, no. 3 (Geology and Mining Ser. no. 50), $223 \mathrm{p}$.

Landgrebe, D. A., 1971, Systems approach to the use of remote sensing: Purdue Univ., Lab. Application Remote Sensing, LARS Inf. Note 041571, $40 \mathrm{p}$.

Ransome, F. L., 1909, The geology and ore deposits of Goldfield, Nevada: U.S. Geol. Survey Prof. Paper 66, 258 p.

Ross, H. P., Alder, J. E. M., and Hunt, G. R., 1969, A statistical analysis of the reflectance of igneous rocks from 0.2 to 2.65 microns: Icarus, v. 11 , no. 1 , p. $46-54$.

Rowan, L. C., 1972, Near-infrared iron absorption bands: Applications to geologic mapping and mineral explora- tion: Annual Earth Resources Program Rev., 4th, Houston, Tex., 1972, p. 60-1 to 60-18.

1973, Iron-absorption band analysis for the discrimination of iron-rich zones: U.S. Geol. Survey open-file report, $23 \mathrm{p}$.

Rowan, L. C., and Vincent, R. K., 1971, Discrimination of iron-rich zones using visible and near-infrared spectral analysis [abs.]: Geol. Soc. America, Abs. with Programs, v. 3 , no. 7 , p. 691 .

Searls, Fred, Jr., 1948, A contribution to the published information on the geology and ore deposits of Goldfield, Nevada: Nevada Univ. Bull., v. 42, no. 5 (Geology and Mining Ser. no. 48) 24 p.

U.S. National Aeronautics and Space Administration, Goddard Space Flight Center, 1971, Data users handbook [for Earth Resources Technology Satellite]: U.S. Natl. Aeronautics and Space Admin., Goddard Space Flight Center Doc. 71SD4249 [loose-leaf, variously paged].

Vincent, R. K., and Thompson, F. J., 1972, Discrimination of basic silicate rocks by recognition maps processed from aerial infrared data, in Seventh Internat. Symposium on Remote Sensing of Environment, Proc., V.1: Ann Arbor, Mich., Univ. Michigan, Inst. Sci. and Technology, Willow Run Laboratories, p. 247-252.

[Whitaker, E. A.] 1965, Colors and the meso-structure of the maria, in Heacock, R. L., and others, Ranger VII, Part II, Experimenters' analyses and interpretations: California Inst. Technology, Jet Propulsion Lab. Tech. Rept. 32-700, p. 29-39.

White, W. B., and Keester, K. L., 1966, Optical absorption spectra of iron in rock-forming silicates: Am. Mineralogist, v. 51, nos. 5-6, p. 774-791.

Yost, E., Anderson, R., and Goetz, A. F. H., 1973, Isoluminous additive color method for the detection of small spectral reflectivity differences: Photog. Sci. and Engineering, v. 17, p. 117-182. 




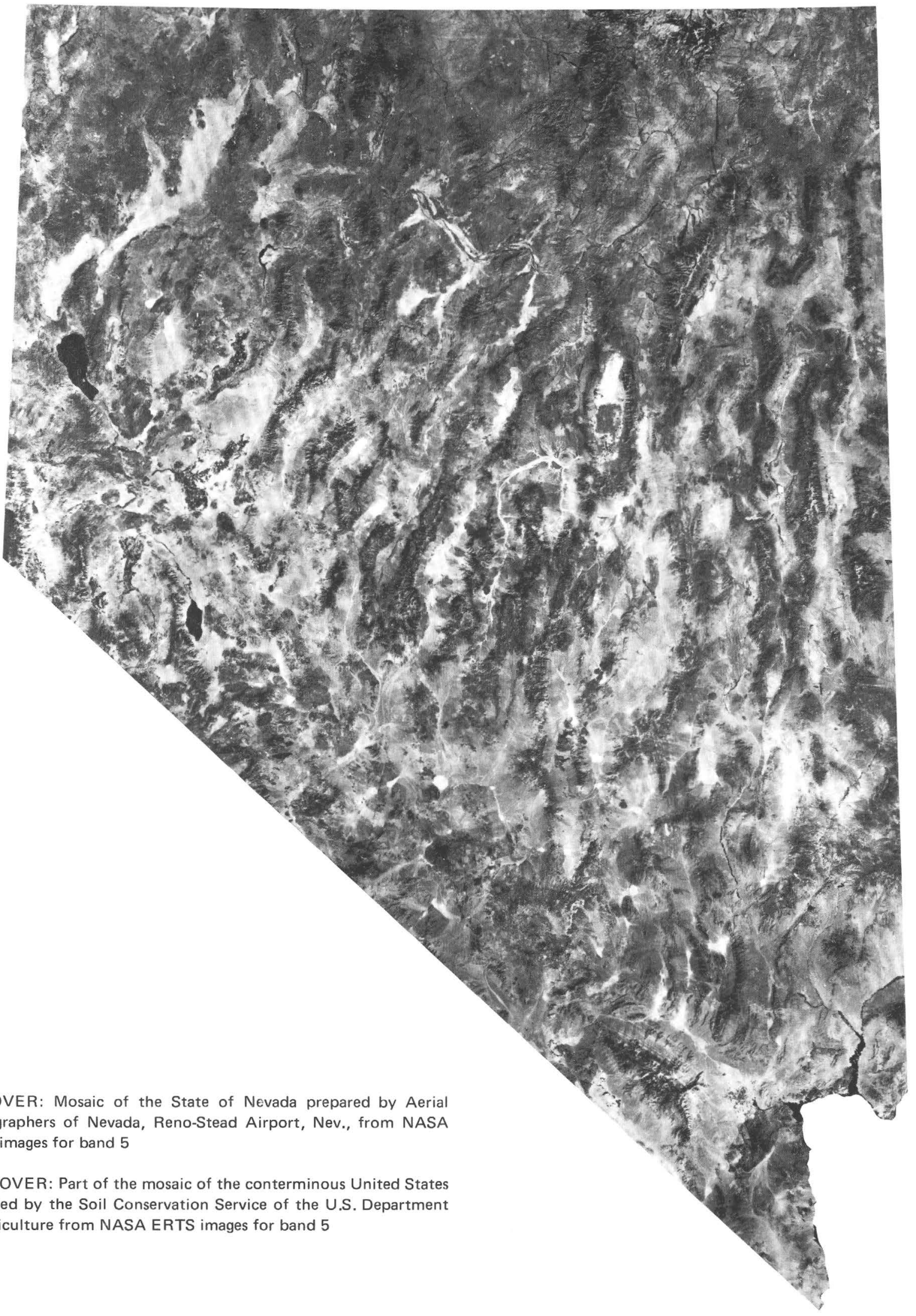

BACK COVER: Mosaic of the State of Nevada prepared by Aerial Photographers of Nevada, Reno-Stead Airport, Nev., from NASA ERTS images for band 5

FRONT COVER: Part of the mosaic of the conterminous United States compiled by the Soil Conservation Service of the U.S. Department of Agriculture from NASA ERTS images for band 5 